\title{
2019 AMERICAN TELEMEDICINE SESSION SUMMARIES (ABSTRACTS)
}

\author{
Jointly provided by

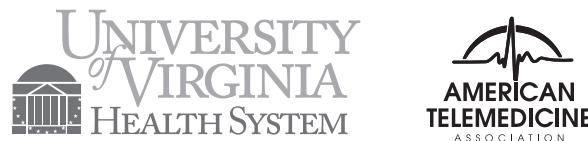 \\ NEW ORLEANS, LA \\ APRIL 14-16, 2019
}




\section{Interactive Breakout}

\section{IB-01}

\section{BOLD HOME CARE SUCCESS WITH VIRTUAL CARE-ENABLED REMOTE MONITORING PROGRAM}

Description: Trinity Health At Home is shaping the future of healthcare and empowering patients. In 2017, the national, non-profit, Catholic home care and hospice organization introduced a pioneering care model and Home Care Connect ${ }^{\mathrm{TM}}$, an integrated virtual care-enabled remote monitoring program with its own 24-7 virtual care center. The goals were to provide in-the-moment, proactive clinical intervention around the clock to reduce its 30-day hospital readmission rate to single digits and greatly enhance the patient and family experience.

Trinity Health At Home is achieving both goals. The virtual care center, staffed by more than 30 specially-trained Trinity Health At Home nurses, is an integral part of the care team, working closely with the field and office-based care teams.

More than 16,000 patients nationwide have benefitted from the program and virtual care center nurses have had more than 65,000 virtual calls with patients. About $98 \%$ of patients surveyed reported they were satisfied with the experience and about 96\% would recommend Home Care Connect to other people.

President and CEO Erin Denholm will share the key factors to the program success - from selecting the right technology to building the foundation for the virtual care center to data collection and analysis and their key learnings in their journey.

SPEAKER: Erin Denholm (Trinity Health At Home)

Session Theme: Home health virtual care $\bullet$ Older adults and aging in place $\bullet$ Populations in value-based care models

Key Learning Objectives:

1. How Trinity Health At Home launched a national successful remote monitoring and virtual care program that is reducing preventable ER visits and hospitalizations and increasing patient engagement and satisfaction for home care patients.

2. Summarize how a virtual care-enabled remote monitoring program benefits patients, their family members, and care teams.

3. Describe the elements required for an effective virtual care center that can accommodate patients at population scale.

4. Describe the elements required for remote monitoring technology easy enough for any patient to use for daily self-reporting.

Key Actions for Participants to Implement:

1. Identify three key actions from this session that participants would be able to implement when they return to the workplace.

2. Better understanding of remote monitoring technology options.

3. Evidence/case study to report to colleagues to support further exploration into implementation of a virtual care program at their organization.

Keywords: virtual care, remote monitoring, home care, home health

\section{IB-02}

INTERNET OF MEDICAL THINGS: ANALYTICAL INNOVATIONS FOR REAL-TIME HEALTH AND WELLNESS MONITORING

Description: There is significant potential for IoT technologies to impact health and wellness. A key enabler is the capture and analysis of streaming data in real-time generated from connected devices such as monitors, wearables and sensors. We will review research conducted with North Carolina State medical researchers and its analytical innovations on healthcare use cases.

SPEAKERS: Nav Ranajee (SAS), Dev Kakde (SAS)

Session Theme: A critical success factor for IoT in Healthcare is the ability to capture and analyze streaming data in real-time.

Key Learning Objectives:

1. Learn about the current state of IoT in Healthcare.

2. Hear about IoT use cases.

3. Learn about best practices in IoT streaming analytics.

Key Actions for Participants to Implement:

1. With the knowledge of IoT applications the participant can identify use cases for their organization.

2. Understanding of streaming analytics.

3. IoT implementation do's and don'ts.

Keywords: IoT, Internet of Things, Internet of medical things, streaming analytics

\section{IB-03}

\section{NATIONAL TELEHEALTH CENTERS OF EXCELLENCE: WHO ARE THEY AND WHAT DO THEY DO}

Description: The Health Resources and Services Administration (HRSA) has designated two National Telehealth Centers of Excellence. These cooperative agreement awards were designed to support rigorous scientific evaluation of telehealth programs at two academic medical centers in rural states with particularly high rates of chronic disease. The designees both demonstrated long standing telehealth programs with both breadth and depth and the ability to study the outcomes of these programs in order to inform public policy and overcome barriers to widespread telehealth implementation.

The Medical University of South Carolina (MUSC) has devoted its Center of Excellence Resources in year one to 3 main areas of study: (1) The impact of telehealth on federal and local healthcare spending, (2) patient and provider engagement, and (3) decreasing technological barriers to widespread adoption of telehealth. In year two MUSC has expanded this work plan to include an implementation science approach to evaluating telehealth program success, a menu of services to fit the needs of primary care providers and an evaluation of mental health focused programs.

The University of Mississippi Medical Center Telehealth Center of Excellence has focused its year one funding on building a research infrastructure to evaluate multiple aspects of remote patient monitoring as well as the Telehealth impact on rural providers. The focus in year two has expanded to include evaluation of multiple telehealth programs including specialty telemedicine, store and forward dermatology, remote patient monitoring and education and outreach. The University of Mississippi will also be researching telehealth and community economic development.

These complementary work plans and early outcomes will be discussed as well as ways that both new and experienced telehealth programs may interact and benefit from this work will be presented.

SPEAKER: Kathryn King Cristaldi (Medical University of South Carolina, Center for Telehealth) and Richard Summers, MD (The University of Mississippi Medical Center) 


\section{INTERACTIVE BREAKOUT}

Session Theme: Telehealth in Action Key Learning Objectives:

1. Identify the two National Telehealth Centers of Excellence and fully understand how they fit into the national telehealth landscape.

2. Discuss the work plans for large-scale telehealth evaluation that the National Telehealth Centers of Excellence have undertaken.

3. Explore early outcomes and how these Centers can help support telehealth evaluation, implementation and policy nationwide.

Key Actions for Participants to Implement:

1. Identify federally supported resources that meet the needs of the participant's organization.

2. Recognize ways the organization is collecting metrics that may help to overcome barriers to widespread telehealth adoption.

3. Discern processes by which the National Telehealth Centers of Excellence may be able to benefit the organization.

Keywords: National Telehealth Center of Excellence, HRSA, evaluation, cost analysis, healthcare spending, support resources, MUSC, UMMC

\section{IB-04}

\section{ADDRESSING PSYCHIATRIC SHORTAGES IN RURAL COMMUNITIES WITH A DIVERSE MODEL OF CARE DELIVERY AND TRAINING}

Description: Throughout the nation, access to traditional psychiatric services has become an escalating concern. The problem is worsened by an ongoing national shortage of psychiatrists and an increasing need for behavioral health services. The rural areas of our country have been hit particularly hard due to a lack of community psychiatrists and the difficulties of transportation, whether by a distance or financial barrier. Because of this, University of Pittsburgh Department of Psychiatry and UPMC Western Psychiatric Hospital (WPH) created the telepsychiatry division in 2007 with the goal of expanding access to high-quality psychiatric care. The program uses secure, synchronous videoconferencing technology to perform face-to-face psychiatric care across distances. At WPH, telepsychiatry is a multi-faceted program and includes a variety of services to meet our patients' needs. To date we have completed over 45,000 telepsychiatry visits into 17 counties throughout Pennsylvania via multiple models of care:

- outpatient psychiatric care in rural mental health clinics

- psychiatric consult \& liaison services within medical hospitals

- psychiatric inpatient services

- psychiatric care into nursing homes

- direct to consumer services

We employ 23 telepsychiatrists with expertise in many clinical arenas: adult, geriatrics, child and adolescence, women's mental health, consult and liaison, psychosis, anxiety disorders, intellectual disabilities, community psychiatry, addiction medicine, academic psychiatry, etc. Each doctor is carefully chosen using the same criteria as in-person psychiatrists at the WPH and our affiliated UPMC community hospitals. Our telepsychiatry team members are not only a part of our virtual academic community, they are part of the communities and clinics we serve throughout Pennsylvania.

In this session we will focus on challenges in telepsychiatry care delivery, strategy for expansion, methods for physician engagement, the creation of a virtual academic community, and training the next generation of telepsychiatrists.

SPEAKERS: Gina Perez (UPMC Western Psychiatric Hospital)
Session Theme: Telehealth in Action; New Frontiers and Emerging Best Practices in the Application of Telehealth.

Key Learning Objectives:

1. Participants will identify multiple care delivery options for telepsychiatry.

2. Participants will learn several techniques for creating a virtual community for telepsychiatrists.

3. Participants will learn a format for structuring resident learning of telemedicine.

\section{Key Actions for Participants to Implement}

1. Identify care delivery models in rural outpatient mental health clinics.

2. Identify methods for physician engagement within a telepsychiatry division.

3. Identify basic components of a telepsychiatry elective for residents.

Keywords: telepsychiatry, electives, academic

\section{IB-05}

\section{CREATING INNOVATION THROUGH DISCIPLINE AND CREATIVITY}

Description: Understand the unique balance of discipline and creativity essential in entering into the introduction of new healthcare delivery models. Journey through the process of how one integrated health system worked within the current trends of penalty and incentives to successfully implement a virtual care model that enlist change management skills to carefully craft innovative solutions.

This journey includes moving through an integrated health system with two different health plans and multiple regionalized structures, plus hundreds of customer contracts, federal and 20 + state requirements, as WELL as other external markets and stakeholders. The unwavering goals and objectives of the program kept a discipline and sense of innovation wrapped into determining how to apply consistent care standards to improve quality and costs in a highly regulated industry. Delivery of this virtual care model has resulted in a care delivery that is improving costs of care, enhancing care outcomes and is supporting recruitment and retention of providers.

The discipline to develop a solution to the identified problem, while allowing innovation to occur created Avera eCARE.

SPEAKERS: Deanna Larson (Avera eCARE) and Jay Weems (Avera eCARE)

Session Theme: Trends and ideas that are driving the industry - Implementing a virtual care model within a health system.

Key Learning Objectives:

1. Understand the importance of discipline and creativity when creating innovative models within an integrated health system.

2. Discuss barriers, successes and outcomes experienced within 25-years of providing virtual care.

3. Identify how specific health system challenges were solved through innovation and a new model of care delivery.

Key Actions for Participants to Implement:

1. Understand the importance of change management when introducing virtual care.

2. Understand the importance of identifying specific goals and objectives of a new program, while always focused on improving patient quality.

3. Understand how to develop innovative solutions to health system challenges.

Keywords: health system, telemedicine, telehealth 


\section{INTERACTIVE BREAKOUT}

\section{IB-06}

\section{CROSSING STATE LINES, LICENSE PORTABILITY AND TELEHEALTH}

Description: When telehealth providers electronically cross state lines to care for patients in other states, they typically need multiple licenses. This has long been recognized as a challenge in the practice of telehealth and in 2002 Congress created a program in the Office for the Advancement of Telehealth (OAT) in the Federal Office of Rural Health Policy at HRSA to support innovative approaches in license portability. A number of organizations and licensing boards have developed models and mechanisms to reduce the licensing burden of multi-state practice. This panel features representatives of several models to discuss the status of their programs and plans for this important telehealth issue.

SPEAKERS: William England (Heath Resources and Services Administration); Lisa Robin (Federation of State Medical Boards); Janet Orwig (Association of State \& Provincial Psychology Boards); and James Puente (National Council of State Board of Nursing)

Session Theme: Multi-state practice of telehealth (Telehealth in Action)

Key Learning Objectives:

1. Understand opportunities for multi-state licensure in different health professions.

2. Learn the status of different states in implementing multi-state compacts and models.

3. Understand challenges that have been resolved or may remain in multi-state practice.

Key Actions for Participants to Implement:

1. Apply for a multi-state license in their field if available.

2. Track or support plans to implement multi-state licensing in their state.

Keywords: HRSA, licensure, OAT, FORHP

\section{IB-07}

\section{DIRECT TO CONSUMER: LEGAL AND REGULATORY ISSUES FOR ENTREPRENEURS}

Description: There is a new wave of direct to consumer and asynchronous virtual care services spreading over the country. Opportunities abound, and while many entrepreneurs focus on medical board rules, they must think bigger and address a full suite of legal requirements in connection with selling healthcare services and items. There are numerous regulatory issues and complexities when creating a telemedicine company, particularly if the company wants to deliver direct to consumer services across states or even countries. But solutions exist and entrepreneurs and investors can build models that not only make good business sense, but also adhere to these legal requirements across states.

Using real world case studies, this session will provide entrepreneurs, start-ups, and emerging companies with a high-energy and engaging discussion addressing the legal landscape necessary to create a direct to consumer virtual care offering. It will educate and empower attendees with the knowledge to build their company the right way on strong footing. We will cover business structure, investments in medical groups, fraud and abuse laws, asynchronous prescribing, contracting with pharmacies/labs, and building an e-commerce platform for online medical services. The content will be squarely focused on direct-to-consumer, and not business-to-business or facility arrangements.

SPEAKERS: Nathaniel Lacktman (Foley \& Lardner LLP)
Session Theme: Trends and ideas that are driving the industry.

\section{Key Learning Objectives:}

1. Understand and apply the laws and rules to build a direct-to-consumer telemedicine or virtual care company across the United States.

2. Engage in meaningful discussion of regulatory issues specifically tailored to direct-to-consumer entrepreneurs.

3. Learn how to offer clinically valid asynchronous telemedicine services and not substandard internet prescribing.

Key Actions for Participants to Implement:

After the session, participants will be able to:

1. Articulate the difference between clinically valid asynchronous telemedicine and substandard internet prescribing.

2. Know the business models and structures legally required to create a multistate telemedicine company.

3. Identify new opportunities and conditions to offer consumers meaningful, scalable telehealth services.

Keywords: Direct-to-consumer telemedicine, telehealth entrepreneurs, telehealth law

\section{IB-08}

\section{ENTERPRISE VIRTUAL HEALTH: FROM MANY TELEMEDICINE PROJECTS TO ONE PROGRAM}

Description: NYU Langone Health leadership established a strategic goal of developing a high-growth Virtual Health program to enhance the patient experience, reduce expenses, and improve operational efficiency. With this direction, we morphed from multiple telemedicine projects to a thoughtfully implemented Virtual Health Program. The two most important factors were the scalability of the technology and that the solutions integrate seamlessly with the single instance Epic EHR. The Virtual Health Steering Board was created to govern the programmatic development.

We engineered a scalable program by centralizing strategic decision-making within Health System IT, with the CMIO and the CTO acting as the programmatic business sponsors. We seamlessly integrated telemedicine workflows into the EHR and patient portal with our virtual urgent care. We expanded direct-toconsumer video visit services to more than 350 providers in specialties such as surgery (general, orthopedic, cardiothoracic, and gynecologic), oncology, weight management, gastroenterology, cardiology, FQHC school-based services, and more. We continue to expand these standard tools to other services.

A Virtual Health IT team was formed to facilitate the necessary focus to build a scalable program. This included a core team of the Virtual Health Director, 3 analysts, and a project manager, in addition to a multidisciplinary team of other application analysts.

Solutions have also been architected for freestanding Emergency Departments. Telemedicine carts were placed in the EDs, and are leveraged by remote specialists for services such as telestroke and telepsychiatry to provide emergent treatment from their smartphone or tablet using our standard Cisco Jabber video infrastructure. We also deployed in-room tablets for providers to initiate on-the-fly telemedicine encounters with any patient in one of our 500+ inpatient rooms.

We've completed $25+$ projects since the program's inception and have surpassed 6,000 outpatient video visits with monthly volume growth of $12 \mathrm{x}$ in 18 months. Our average patient satisfaction score is $4.7 / 5$ stars.

SPEAKERS: Jason Sherwin, MBA (NYU Langone Health) and Paul Testa, MD, JD, MPH (NYU Langone Health)

Session Theme: Tools and techniques for building innovation and engagement. 
Key Learning Objectives:

1. Develop an understanding of the necessary programmatic governance to develop a scalable virtual health strategy that will improve the patient experience, reduce expenses, and improve operational efficiency.

2. Leave with a toolkit for clinical oversight and training to facilitate telemedicine project implementations.

3. Understand why a dedicated internal Telemedicine IT Support team that provides real-time support is necessary for maximizing patient and provider satisfaction.

Key Actions for Participants to Implement:

1. Develop your own scalable Virtual Health program

2. Identify the key decision points in selecting the right technological platforms for your institution

3. Create a dedicated internal Telemedicine Support team to provide realtime technical support for your patients and providers

Keywords: program development, electronic health record (EHR) integration, virtual urgent care

\section{IB-09}

\section{HEALTH COMMUNICATION: DESIGNING EFFECTIVE MESSAGES}

Description: This interactive session will involve an overview of the use of health communication and advertising perspectives on the development of effective health messages, demonstrate through several short case studies how the application of these approaches can be implemented, and provide attendees an opportunity to apply these ideas in an interactive exercise.

SPEAKERS: Michael Mackert, PhD (The University of Texas at Austin)

Session Theme: The session will focus on the effective design of health messages, grounded in the perspective of consumer insights and advertising. Key Learning Objectives:

1. Identify the fundamental steps of health communication campaign design.

2. Characterize the advertising/account planning approach to user-driven campaign design.

3. Understand the use of personas and creative briefs to articulate the strategy for a health communication campaign.

Key Actions for Participants to Implement.

1. Use simple tools for developing more effective health messages.

2. Apply a perspective of user-centered health messaging.

3. Understand the difference between research/data and consumer insights.

Keywords: health communication, advertising, e-Health

\section{IB-10}

HEAR FROM CMS ON MEDICARE REIMBURSEMENT: VIRTUAL CARE CODES, RPM, AND TELEHEALTH SERVICES

Description: CMS introduced monumental changes to Medicare coverage of telemedicine and virtual care, announcing four new categories of codes: virtual check-ins, asynchronous evaluation of video and images, internet interprofessional consults, and remote patient monitoring. CMS explained the impetus for the bold new codes, declaring: "We now recognize that advances in communication technology have changed patients' and practitioners' expectations regarding the quantity and quality of information that can be conveyed via communication technology. From the ubiquity of synchronous, audio/video applications to the increased use of patient-facing health portals, a broader range of services can be furnished by healthcare professionals via communication technology as compared to 20 years ago." These codes went live January 1, 2019, but many providers remain uncertain about how and when they should use these codes. ATA is honored to have two CMS lawyers who wrote these new regulations join us at ATA19 as presenters. Attendees will hear first-hand about coverage and reimbursement for these new codes, as well as engage in Q\&A with the presenters.

SPEAKERS: Emily Yoder (CMS)

Key Learning Objectives:

1. Understand the new Medicare virtual care services codes introduced this year, including virtual check-ins, asynchronous evaluations, interprofessional consults, and remote patient monitoring.

2. Hear answers to some of CMS' frequently asked questions on telehealth services under the Medicare program.

3. Develop the confidence to offer these new virtual services to patients and bill the Medicare program

\section{IB-11}

\section{INSPIRED AGING AND VIRTUAL CARE TRANSFORMATION AT BAYCREST HEALTH SCIENCES}

Description: “Inspired Aging”, Baycrest's new five-year strategic plan, embeds virtual care in the pursuit of its mission to tackle the public health challenge of dementia and chronic care in an aging world. This strategic priority builds on numerous point-of-care clinical initiatives, beginning in 2016, to design and pilot modalities of virtual care aimed at a diverse set of clients and care settings: hospital patients (eConsult with specialists), nursing home residents (palliative care and behavior support outreach), outpatients (virtual home assessment and memory clinic), homebound frail seniors (geriatrician and geriatric psychiatry visits, 24/7 primary care), caregivers of people with dementia (virtual counselling groups and individual caregiver support), and cognitive neuroscience translational research participants (goal management training). These projects helped the academic health sciences center to conceptualize virtual care as a new 'environment of care', integrated with the various capabilities of all other care environments at Baycrest.

Virtual care is now a cornerstone of Baycrest's transformational journey to introduce innovative residential and healthcare delivery models for older adults and their families. We envision a future where Baycrest will 'pivot' from being a healthcare facility that provides some community-focused virtual services, to a virtual healthcare organization that has some physical infrastructure to support the segment of the population that needs it. “Baycrest@Home” will deliver a portfolio of direct and virtual technology-enabled home care and community-based activities supporting frail older adults.

Two leaders who are instrumental in this bottom-up and top-down approach will share the story of Baycrest's organic roll-out of virtual care services that informed the strategic plan. Facilitated participant engagement will ensure that you emerge from the session with insights from Baycrest's story that can be applied to your work, your organization, and your care environment. 


\section{INTERACTIVE BREAKOUT}

SPEAKERS: Jagger Smith (Baycrest Health Sciences) and Simon Cheesman (Baycrest Health Sciences)

\section{Session Theme: Telehealth in Action}

Key Learning Objectives:

1. Reflect on insights from the organic roll-out of virtual care services that informed the strategic plan and a new business model at Baycrest, a geriatric-focused academic health sciences center in Toronto, Canada.

2. Understand adaptive implementation techniques for simultaneous application of virtual care in multiple locations (hospital, outpatient, residential, home and community) for varied uses (geriatric medicine, caregiver support, and chronic disease).

3. Envision a new virtual healthcare environment co-designed with older adults to deliver outcomes that matter to vulnerable, disenfranchised patients aging in place.

Key Actions for Participants to Implement:

1. Envision the virtual care environment for older adults in the participant's local context.

2. Apply adaptive implementation techniques.

3. Influence the virtual care strategic plan in the participant's organization.

Keywords: seniors, strategy, hospital

\section{IB-12}

\section{INTEGRATING DIGITAL HEALTH INTO MAINSTREAM CLINICAL PRACTICE}

Description: Implementation and Quality Science of Integrating AI into Mainstream Clinical Practice Acceptability and Use of Innovative Technology by Healthcare Providers at the sharp end of clinical care is challenging even in the face of supporting evidence. This session will highlight and explain the importance of applying implementation and quality science strategies to accelerate adoption of telehealth tools in routine healthcare practice and policies. Discussion will include principles and methods for change management, team intelligence, rapid cycle adaptation and collaborative learning. After the session, the audience will have an implementation roadmap to adapt and use in their institutions.

\section{SPEAKERS: John Chuo, PhD (Children's Hospital of Philadelphia)}

Session Theme: Using change management and quality science principles to implement Telehealth in mainstream clinical practice.

Key Learning Objectives:

1. Know the Quality Domains that can serve as outcome targets for telehealth.

2. Apply systems thinking for implementing telehealth.

3. Apply change management practices for successful telehealth implementation.

Three Key Actions for Participants to Implement

1. Use a PDSA cycle template to execute rapid adaptation.

2. Apply change management principles.

3. Identify Value-based outcome targets.

Keywords: Implementation science, change management, telehealth

\section{IB-13}

\section{LEVERAGING TELECONSULTATIONS: A POWERFUL MODEL TO ADDRESS PHYSICIAN SHORTAGES IN RESOURCE-LIMITED AND HUMANITARIAN SETTINGS}

Description: One of the biggest challenges for health in resource-limited and humanitarian settings is the shortage of trained clinicians and care team members. This has resulted in an increase in medical care for complex patients being provided by overwhelmed care teams with less access to specialized healthcare resources or networks.

In this workshop, 3 organizations leading telehealth innovation in international telemedicine will showcase how their telehealth solutions aid clinical team members in the transfer of knowledge to support hard to reach care for their patients. Through collective experience, asynchronous teleconsultations improve the quality and level of care provided in underserved communities while still leaving the management of patients in the hands of local clinical care team members.

- The Addis Clinic connects frontline health workers in remote and underserved communities around the globe to a virtual network of volunteer physicians using an app-based teleconsultation platform.

- RubiconMD democratizes medical expertise by bridging the gap between primary and specialty care through a web and app-based eConsult platform and supports technology implementation through a Clinical Transformation in Technology framework.

- Médecins Sans Frontières (MSF) has developed a multilingual telemedicine network to assist its medical teams often working in isolated or hard to reach locations by providing direct access to specialist advice using a webbased messaging system and store-and-forward communication.

The transfer of knowledge is the most impactful use of telemedicine on the international scale to reduce the impact of clinician shortages around the world. Through mobile application and web-based telemedicine platforms, each organization will showcase how their telehealth solutions and/or frameworks support local clinicians and care teams through remote, asynchronous teleconsultations via access to highly skilled specialist networks.

SPEAKERS: Michelle Turner (The Addis Clinic); Sophie Delaigue (Médecins Sans Frontières / Doctors Without Borders); and Lisa Bard Levine, MD, MBA (The MAVEN Project); Gil Aldo (RubiconMD)

Session Theme: International Telemedicine Clinician to Clinician Teleconsultations Asynchronous Low-Resource.

Key Learning Objectives:

1. Engage in dialogue regarding ethical and logistical hindrances of direct to patient cross-border telemedicine.

2. Understand how various models of an international teleconsultation program can result in a reduction of need for short-term clinicians in underserved areas and the importance of focusing on long-term clinical solutions.

3. Discuss solutions to address the challenges of remote teleconsultations including the differences in resource availability and the lack of clear policies on international telehealth.

Key Actions for Participants to Implement:

1. Adapt technology to meet the unique needs of clinicians and patients in under-resourced settings.

2. Implement teleconsultation initiatives to tackle unequal access to care around the globe.

3. Execute key strategies to build and train a volunteer network of physicians utilized in an international teleconsultation program.

Keywords: international, asynchronous, teleconsultations 


\section{IB-14}

\section{OPERATIONAL CONSIDERATIONS FOR RESPONDING TO INCREASED DEMAND FOR TELEMENTAL HEALTH SERVICES}

Description: The session will begin with a discussion from Scott Ashwood, a RAND researcher who has published widely on telehealth, on trends in telemental health use nationally, including data on whether clients choosing to use telehealth are new healthcare consumers or are existing users opting for a new mode of care delivery. Next, Rajeev Ramchand, Sr. Vice President of Research at Cohen Veterans Network (CVN), a network of behavioral health clinics offering low- or no-cost behavioral healthcare to veterans and their families, will describe their network's experience offering telemental health, including data on patients who are exclusive telemental health users, those who convert to telemental health during the course of treatment, or those who toggle between the two modes of care. Both speakers will then discuss how behavioral healthcare providers offering telehealth have shifted or are considering changing existing operational procedures to better accommodate trends in demand for telemental health. This includes changes in recruiting (e.g., remote work solutions to be able to recruit providers across a state), staffing (e.g., hiring more providers to accommodate increased demand), workspaces (e.g., smaller footprint for providers who are exclusive telehealth providers), and network solutions (e.g., staffing to continuously monitor and update telehealth software and ensure appropriate data safeguards). Audience members will be encouraged to ask questions throughout the presentation with time set aside at the end for them to share their own experiences in accommodating telemental health demand or implementing telemental health solutions.

SPEAKERS: Scott Ashwood (RAND Corporation) and Rajeev Ramchand (Cohen Veterans Network)

Session Theme: Telehealth in action

Key Learning Objectives:

1. Identify national trends in demand for telemental health use and whether (and to what degree) this represents new clients or existing clients substituting the way they receive care.

2. Explain patterns of telehealth use among veterans and their families within one network of outpatient behavioral healthcare providers.

3. List new options in staffing and operations that mental healthcare providers are considering to better engage clients in evidence-based care via telehealth.

Key Actions for Participants to Implement.

1. Providers and industry representatives can use data to inform current practices.

2. Providers can consider operational changes to better accommodate increased telemental health demand.

3. Industry representatives can design new approaches to help healthcare providers transition to increased demand for telemental health services more effectively.

Keywords: mental health, veterans, operations

\section{IB-15}

\section{PLAY IT AGAIN SAM: LESSONS FROM OTHER INDUSTRIES}

Description: Healthcare isn't the only industry to undergo a digital transformation. Shopping became e-commerce, tellers were largely replaced by online banking, and travel agencies are nearly extinct. What lessons can telehealth learn from other industries - and how can we innovate in a way that results in a meaningfully better experience for consumers?

SPEAKERS: Sam Glick (Oliver Wyman)

Key Learning Objectives:

1. Understand lessons from other industries and how to apply them to telehealth.

2. Expand thinking about the opportunities for telehealth to improve the consumer experience.

3. Approach problems from a consumer-first mindset rather than a technology-first one.

\section{IB-16}

\section{REDUCTION IN MEDICAL EVACUATIONS IN THE MIDDLE EAST AFTER INTRODUCTION OF ASYNCHRONOUS TELECONSULTATIONS}

Description: In June 2017, the 86th Combat Support Hospital (CSH) launched a pilot study on the use of an existing asynchronous provider-to-provider teleconsultation system already used in the Pacific to military medical providers deployed to Iraq, Kuwait, and Syria. Planned training occurred in August 2017, and the pilot study analyzed the rate of routine medical evacuations from these locations in the 3 months before and after program training and implementation. The results of this pilot demonstrated a 56.7\% reduction in medical evacuations, with routine, non-surgical, non-battle injuries representing the majority of cases impacted. This is the first prospective study looking at the impact of a low-cost teleconsultation platform on the deployed Service Members in the Middle East, to include cost avoidance and increased quality of care delivery through teleconsults with clinical experts at military tertiary care centers.

SPEAKERS: Jennifer Mbuthia (Army Medicine)

Session Theme: The use of asynchronous provider-to-provider teleconsultations can have a significant impact on the need for routine medical evacuation from a combat zone.

\section{Key Learning Objectives:}

1. Understanding the logistical challenges involved with routine medical evacuation from an austere location such as a combat zone.

2. Recognize the value-add of giving forward-deployed medical providers access to multiple specialists for clinical advice in a low-bandwidth, HIPAA-complaint, and secure format.

3. Appreciate the benefits of a low-cost, Web-based system for delivering asynchronous teleconsultations to austere, resource-limited environments.

Key Actions for Participants to Implement:

1. Web-based asynchronous teleconsultation tools are highly cost effective for supporting quality medical care to remote and austere locations.

2. Training of new users is important, but an intuitive platform lends itself to enhancing user experience and buy-in.

3. Consider a broad base of specialties to offer for asynchronous specialties from the start.

Keywords: military, asynchronous, medical evacuation

\section{IB-17}

\section{SUCCESSFUL HEALTH SYSTEM MOTIVES IN DIRECT TO CONSUMER}

Description: Most providers are looking to implement DTC telehealth programs, however struggle to find the appropriate implementation strategies. 


\section{INTERACTIVE BREAKOUT}

Focusing on traditional measurements of ROI derails health systems from implementing DTC services as insurance coverage and increased patient volumes are considerably the wrong reasons for entering the DTC space. Presenters will demonstrate how disruptive innovation plays a role in the success of DTC solutions. A study from NEJM Catalyst labels low insurance coverage rates as the number one barrier to preventing widespread adoption of technology tools for patient engagement. As this may be a concern for traditional telehealth, DTC is not one in the same. This is where health systems are failing in the DTC marketplace - in treating DTC as legacy telehealth. Health systems need to look at the consumer's needs and demands as the primary motivation for implementing DTC solutions. DTC care is about extending provider accessibility, while meeting the convenience patients want not technically about practicing medicine. Speakers will cite a RAND study to demonstrate that traditional ROI calculations will not showcase surface success in DTC solutions. The article shows that " $12 \%$ of DTC telehealth visits replaced visits to other providers, and 88\% represented new utilization." On the surface, these findings are negative as new utilization traditionally equates to greater costs. However, health systems need to think about DTC solutions differently. Think about DTC as you would a managed diabetic patient population. Pharmacy spending for this population goes up and if this is all that was looked at, the managed diabetic population would be seen as an increased cost. However, when looking at the bigger picture, total medical spending of a well-managed diabetic population drastically lowers. This is how health systems need to think about DTC - it's about delighting and engaging patients to convert them longitudinally.

SPEAKERS: Nate Gladwell (University of Utah Health)

Session Theme: Direct-to-consumer telehealth strategies should be approached differently than legacy telehealth strategies.

\section{Key Learning Objectives:}

1. Explain the traditional motives for implementing a telehealth strategy into a health system and why these motives do not work when entering the direct-to-consumer (DTC) telehealth space, making use of the value equation: value $=$ quality + service $/$ cost.

2. Identify why employers and insurers have acknowledged DTC strategies and how health systems should position themselves.

3. Demonstrate, through key findings of a RAND survey, that legacy ROI calculations do not suffice in the disruptive innovation of DTC telehealth, while also showing that DTC strategies do have a tremendous benefit on health system costs overall.

Key Actions for Participants to Implement:

1. Shift DTC motivation from simply a cost reduction strategy to the consumer and their needs.

2. Re-strategize their DTC model - DTC isn't about practicing medicine, but extending providers' reach.

3. Think like a "disruptor" - implementing DTC strategies that set themselves apart from the ebb and flow of archaic healthcare engagements.

Keywords: direct-to-consumer telehealth; telehealth strategies; disruptive innovation

\section{IB-18}

\section{TRANSFORMING CRITICAL CARE WITH TELEMEDICINE}

Description: Intensivists are essential to treating the over 55,000 critically ill patients cared for within ICUs every day in the United States (SCCM). Yet by year 2020, merely 22\% of the demand for intensivist services will be met (Journal of the American Medical Association). Dignity Health is using telemedicine to combat this challenge to elevate the level of care rural or smaller facilities can offer, reducing unnecessary transfers and saving costs.

Although telecritical care solutions expand the reach of specialist providers and therefore, the quality of care delivered at any given location, telemedicine is not an end-all solution. The presenters will touch on why Dignity Health has experienced such success in their tele-critical care programs, explaining the importance of building positive relationships between remote providers and local care teams. Building relationships via telemedicine is different from building relationships face-to-face. Remote providers need to be willing to go the extra mile to achieve trustworthy and credulous relationships with local care teams to truly successfully comanage patient care. Additionally, technology to facilitate telecritical care should essentially be invisible so as to not impede clinical workflows. A successful telehealth program not only encompasses reliable technology, but also employs appropriate clinical workflows and positive remote physician-local care team relationships.

The speakers will present several first-hand accounts of success stories to showcase the benefits of telecritical care programs. For example, Celeste Armstrong, Critical Care Nurse Manager, shares how implementing a teleintensivist program helped Woodland Memorial Hospital decrease ICU length of stay to one of the lowest in the Dignity system. The success stories will provide examples of how health systems are continuing to move forward with care as a team and how care teams are mitigating risks with experts driving interventions, as well as stories of staff and provider satisfaction.

SPEAKERS: Denise Pimintel (Dignity Health) and Helen Hawkins, PhD (InTouch Health)

Session Theme: Telecritical care units can gain access to scarce critical care specialists and help improve the quality of care by leveraging physician experts regardless of location.

Key Learning Objectives:

1. Explain the importance of telecritical care units - health systems can expand the reach of remote provider experts using telehealth while also reducing unnecessary transfers.

2. Demonstrate that telemedicine is not an end-all solution by showing that appropriate clinical workflows and positive remote physician/local care team relationships are also essential.

3. Illustrate the success of Dignity Health's telecritical care program by sharing person accounts of clinical success.

Key Actions for Participants to Implement:

1. Recognize the success of telecritical care programs through the clinical success stories we describe.

2. Understand the importance of making remote specialists available in any hospital location, at any time.

3. Describe the importance of implementing appropriate clinical workflows and building positive remote-local care team relationships, in addition to reliable telehealth technology.

Keywords: telecritical care; tele-intensivist; intensive care units

\section{IB-19}

VIRTUAL VISIT: SUCCESSES, LESSONS LEARNED AND DEPARTMENTAL CASE STUDIES

Description: Boston Children's Hospital launched their virtual visit program in January 2017. Since then, they have completed over 3000+ virtual visits and 
have over $200+$ providers trained across $25+$ departments and clinics, with high satisfaction from both patients and providers. Over the time the program has been launched there were many iterations of operations for scheduling, marketing, training, etc. that are responsible for the program's success. Presenters will review the beginnings of the program, and how the team has iterated procedures and practices to achieve long-term success.

Two of the most successful use cases implemented have been postoperative and behavioral health virtual visits. Presenters will highlight case studies in Urology and Psychiatry including number of visits to date, patient experience metrics, provider experience metrics, and highlights of provider personal experiences. Caitlin will highlight Urology's additional research comparing virtual to in-person visits on patient travel, face-toface time with the provider, and overall savings. Dr. Shaligram will review the history of telemedicine in Child Psychiatry, some of advantages in terms of access to care, and results from Boston Children's pediatric psychiatry experience.

SPEAKERS: Caitlin Schumann (Boston Children's Hospital) and Deepika Shaligram, MD (Boston Children's Hospital)

Session Theme: Telehealth in action

Key Learning Objectives:

1. Best practices for building virtual visit infrastructure.

2. How to work effectively across diverse teams.

3. How to assess your program's success.

Key Actions for Participants to Implement.

1. Build the foundation for a direct-to-patient virtual visit program.

2. Assess impact of virtual visits on patient travel, face-time with provider, and overall costs to care.

3. Use the implementation guidelines to streamline telehealth implementations across an enterprise.

Keywords: direct-to-consumer, virtual visits, research

\section{IB-20}

\section{BUILDING A COMPLIANCE PROGRAM IN A VIRTUAL CARE CENTER}

Description: Using the seven elements of the Department of Health and Human Services' (HHS) Office of Inspector General's (OIG) Effective Compliance Program, as outlined in the Federal Sentencing Guidelines, Legal Counsel and Compliance Manager for Mayo Clinic's Center for Connected Care will discuss the establishment of a compliance program that is integrated into its telemedicine center. The Associate Administrator for Connected Care will discuss the value in partnering with Legal and Compliance to integrate best practices within the clinical practice and operational processes.

In addition to being required by the HHS's OIG, an effective compliance program is important for other reasons. An integrated compliance program will bridge the legal requirements with program operations through the incorporation of an effective compliance program into the day-to-day operations. This approach makes compliance a regular part of doing business. Once the program is fully integrated, regulatory compliance increases because it becomes part of the program's daily practices. In addition, in the event of regulatory gaps, an effective compliance program will help to reduce the degree or extent of liability by demonstrating to regulators the good faith efforts to identify, mitigate and prevent non-compliant behaviors and activities.

The development of a sustainable and scalable telemedicine services can be decelerated by a multitude of rapidly-changing legal and regulatory requirements on both state and federal levels. Often the laws and guidance are con- fusing and outdated because they were drafted at a time when telemedicine did not exist, making them difficult to interpret and apply to today's new modalities of healthcare. An embedded practice-oriented compliance program helps to operationalize the regulatory requirements while managing an organization's risk.

SPEAKERS: Megan Olson, JD (Mayo Clinic); Greg Anthony (Mayo Clinic); and Page Underwood, JD (Mayo Clinic)

Session Theme: This session focuses on how operations can successfully implement long-term scalable products and services by partnering with legal and compliance.

\section{Key Learning Objectives:}

1. Understand the 7 elements of an effective compliance program and how they may be used to build a sustainable and scalable compliance program in a virtual care center.

2. Understand legal and regulatory principles relevant to telemedicine and how variations and frequent changes can be managed as part of a compliance program.

3. Understand the operational value in partnering with Legal and Compliance to integrate best practices within the implementation process.

Key Actions for Participants to Implement:

1. Implement a streamlined and standardized compliance/legal review process for telemedicine clinical service implementations.

2. Update and/or implement telemedicine legal/compliance training for staff.

3. From an operational perspective, assess and modify staffing and/or collaboration model with legal and compliance.

Keywords: legal, compliance, implementation

\section{IB-21}

\section{HEALTH CENTERS' JOURNEY TO TELEHEALTH ADOPTION}

Description: Through Health Center Program funding, authorized by Section 330 of the Public Health Service Act, the Health Resources and Services Administration (HRSA) supports the delivery of affordable, accessible, comprehensive, and high quality primary care services to the Nation's high need geographic areas and populations. The nearly 1,400 health centers operate more than 12,000 service delivery sites in every state, the District of Columbia, Puerto Rico, the Virgin Islands, and the Pacific Basin. Nearly 27 million patients, including medically underserved and uninsured patients, received primary healthcare services through the Health Center Program in 2017.

Annually, health centers report to HRSA on clinical quality metrics through a standardized Uniform Data System (UDS). Questions regarding the use of telehealth were introduced to the UDS in 2016. The number and specificity of questions have since increased, giving a clearer picture of telehealth use. According to 2017 data (the most recent available), 44\% of health centers reported using telehealth and another $20 \%$ planned to implement telehealth soon.

With the support of HRSA-funded supplements and technical assistance, health centers are increasingly using telehealth and applying these technologies to a more diverse array of services. This interactive panel will share what is known about health centers' use of telehealth, including summarizing the findings of the December 2018 Health Affairs article describing factors associated with and barriers to telehealth use. Health centers and Primary Care Associations, who are state and regionally-based health center strategic partners, will provide case examples and successful practices, and identify opportunities 


\section{INTERACTIVE BREAKOUT}

that will support health centers' expanded use of telehealth. Audience questions and dialogue will be encouraged throughout by the panel moderator.

SPEAKERS: Shannon McDevitt, MD (Heath Resources and Services Administration) and Ching-Ching Claire Lin, $\mathrm{PhD}$ (Heath Resources and Services Administration)

Session Theme: Telehealth in Action

Key Learning Objectives:

1. Summarize health center telehealth current data and planned future metrics.

2. Describe successful practices employed by health centers to introduce and expand telehealth.

3. Identify opportunities that will support health centers' continued adoption of telehealth

Key Actions for Participants to Implement:

1. Find a health center that offers telehealth services.

2. Use HRSA health center data for research or analysis.

Keywords: HRSA, FQHC, health center

\section{IB-22}

\section{TELEDENTISTRY: TRENDS, CHALLENGES AND OPPORTUNITIES}

Description: Dominion National will present teledentistry trends and opportunities for insurance carriers, dentists, patients and employers. Dominion will share insights from its teledentistry pilot program and new technology trends aimed at improving teledentistry adoption for both patients and dentists. Additionally, Dominion will discuss the impact that teledentistry can have on dental plan utilization, retention and cost savings. The session will also include a live demo of a new, innovative intraoral camera that will significantly improve the teledentistry delivery model.

SPEAKERS: Mike Davis (Dominion National); Jeff Schwab (Dominion National); and Brant Herman (MouthWatch)

Session Theme: Telehealth trends and ideas that are driving care delivery, cost effectiveness and the patient experience

Key Learning Objectives:

1. Participants will learn how teledentistry can result in cost savings for dentists, patients, employers and insurance carriers.

2. Participants will gain insights on teledentistry trends and how teledentistry can impact dental insurance plan utilization and patient/ member retention.

3. Participants will gain insights from Dominion National's teledentistry pilot program as well as experience a live demo of an innovative intraoral camera that can significantly improve the teledentistry delivery model.

Key Actions for Participants to Implement:

1. Bring significant insights and supporting information to help make a case for including teledentistry in their practice, benefits package or insurance program.

2. Associate or project cost savings from teledentistry.

3. Navigate the hurdles of teledentistry, including low adoption rates, regulatory considerations, data security/privacy and operational implications.

Keywords: Teledentistry, Innovation (dental/dentistry), Virtual care

\section{IB-23}

\section{YOU CAN'T DO IT ALL: HOW DO YOU CHOOSE}

Description: This short session will provide attendees with an overview of things to consider when planning Telehealth activities for their organization. This session is meant to leave the participant with food for thought as they work to use their resources wisely and build programs that make sense for their organization.

SPEAKERS: Tearsanee Davis (University of Mississippi Medical Center)

Session Theme: Program Development

Key Learning Objectives:

Participants will:

1. Recognize the dilemma in determining which Telehealth programs to develop.

2. Articulate things to consider when planning priorities.

3. Understand the importance of ongoing evaluation.

Three Key Actions for Participants to Implement:

1. Participants will be able to draft a plan for telehealth activity for their organization based on priorities and resources.

2. Participants will be able to discuss Telehealth needs of their organization with key stakeholders.

3. Participants will be able to articulate the factors that drive Telehealth activity.

Keywords: telehealth program planning

\section{IB-24}

\section{PLATFORMING HEALTHCARE}

Description: Last year, the news that Amazon, Berkshire Hathaway and JP Morgan Chase joined forces to create their own healthcare company rocked the industry. It was a clear signal that healthcare is ripe for disruption and massive change that will put the patient at the center.

"Platform" companies like Amazon, Uber, Airbnb and Netflix disrupt and reconfigure incumbent business practices. They connect suppliers (where costs are) with customers (where the money is) by delivering superior products and services at competitive prices with great customer experience. They prioritize outcomes, not ownership and control.

Healthcare companies that can move quickly to evolve towards being more like a platform business, which builds itself around the needs and expectations of the patient, will be best positioned to adapt to the disruption coming to healthcare.

This session will explore how to be more like a platform company and the role that a thriving, nimble telehealth network plays.

With telehealth, providers are able to seamlessly meet patients where they are at - physically and figuratively, in their health journey. The game changer with telehealth services is that they enable us to move knowledge, not people.

The benefits of building out your telehealth services to stay ahead of the disruption curve include: For providers, the shift to a platform business model frees doctors to focus on what they want to do - keep a patient healthy. It also eases the burden of ownership and control of property; fewer expensive quaternary and tertiary hospitals need be built as a majority of the same care can be provided in critical access hospitals through virtual care coordination. For patients, the lower barriers to entry to see 
INTERACTIVE BREAKOUT

a provider, increases access points, and convenience keep them at the center of care.

SPEAKER: Amy Compton-Phillips, MD (Providence St. Joseph Health)

Session Theme: Focus on the business we are in/ health for a better world

\section{Key Learning Objectives:}

1. Identify actionable changes in practices (understand how to turn variations in practice to action).

2. Understand the benefits of operating like a platform company.

3. Learn the new rules of platform healthcare.

Key Actions for Participants to Implement:

1. How to identify platform opportunities in your health system.

2. How to implement a platform in your current health system.

3. How to identify needs of your patients to build a platform around.

Keywords: innovation, patient-centered, platform

\section{IB-25}

\section{TRANSFORMING CARE ACCESS FOR VETERANS}

Description: Neil Evans will discuss his perspective on how to best serve a unique veteran population through care that is aimed at creating deeper connection and more continuous conversation instead of being aimed solely at saving costs and creating efficiencies.

SPEAKER: Neil Evans, MD (U.S. Department of Veterans Affairs)

Key Learning Objectives:

1. Understand how the right virtual care strategy can remove barriers and actually improve the human connection for a population who needs it most.

2. Determine the unique needs and acuities of the Veteran population that are best served through on-demand, continuous access.

3. Identify the existing barriers in traditional care that make it ineffective, or inconvenient, or even impossible for veterans with unique conditions and social determinants to access the level and type of care needed.
Key Actions for Participants to Implement:

1) Re-examine the communication methods being used to connect with a truly unique veteran population.

2) Know the criteria to keep in mind when assessing virtual care platforms to best serve unique US populations.

3) Identify, and act on improving existing inefficiencies in care pathways for veteran populations.

Keywords: Veterans healthcare, healthcare access, connected care

\section{IB-26}

\section{TELEMEDICINE AND HEALTH PLAN QUALITY IMPROVEMENT}

Description: This session will discuss the intricacies of telemedicine and the impact that it can have on health plans who are earlier adopters. Recently NCQA and CMS have issued continued guidance on the use of telemedicine as a valid form of gap closure tied to performance reimbursement measures and HEDIS value sets. This round table discussion will focus on how these new rule changes have evolved and what the potential impact is to health plans who are working on comprehensive telehealth strategies.

SPEAKER: Anthony Davis (UPMC Healthplan)

Session Theme: Analyzing the impact that telemedicine can have on HEDIS gap closure and health plan quality performance rates.

Key Learning Objectives:

Participants in this session will gain a comprehensive understand and insight into

1) How telemedicine can help health plans close gaps in care.

2) Appropriate billing and infrastructure set-up.

3) The evolution of where telemedicine is heading from a QI perspective.

\section{Key Actions for Participants to Implement:}

1) How to strategically launch telehealth outreach.

2) An understanding of what measures telehealth can impact.

3) How systems can be configured to allow for telehealth code capture.

Keywords: telehealth, HEDIS/NCQA, quality 


\section{Express Talk}

\section{ET-27}

\section{FROM BATTLEFIELD TRAUMA CARE TO BEHAVIORAL HEALTH: CAN THE U.S. MILITARY'S EXPERIENCE PROVIDE A TELEMEDICINE ROADMAP FOR INDUSTRY?}

Description: The link between medical innovation and the U.S. Military has been well documented throughout history. Telemedicine has proven to be no exception. Realization of telemedicine's potential in the military has been born out of necessity, evidence-based through the support of dedicated research, and enabled by a permissive environment that is largely free of commercial barriers such as reimbursement policy and interstate regulation. What can the healthcare industry learn from the military and its application of virtual care? How can we apply those lessons in the broader civilian setting in a healthcare system that is increasingly focused on value?

\section{SPEAKERS: James Geracci, MD (Ascension Healthcare)}

Detailed Session Summary: The link between medical innovation and the U.S. Military has been well documented throughout history. Telemedicine has proven to be no exception. Realization of telemedicine's potential in the military has been born out of necessity, evidence-based through the support of dedicated research, and enabled by a permissive environment that is largely free of commercial barriers such as reimbursement policy and interstate regulation. What can the healthcare industry learn from the military and its application of virtual care? How can we apply those lessons in the broader civilian setting in a healthcare system that is increasingly focused on value?

\section{ET-28}

PROFESSIONAL WEB-SIDE MANNER IN TELEMEDICINE: REAL-LIFE APPLICATION FOR VIDEO VISITS, ACUTE CARE AND SECURE MESSAGING

Description: There is extensive information published and available to clinicians and operational staff in relation to telehealth, how they can set-up their technology troubleshoot issues, and how to integrate it within their current practice. However, there is currently little information provided in relation to professionalism or web-side manner within telehealth and how clinicians should conduct and present themselves throughout the interaction with patients, caregivers, or other clinicians at a different health site they might be consulting with to provide care to a patient.

Professionalism within telehealth is extremely important, since telehealth has not been fully adopted and it is still a growing portion of healthcare. The ability for a patient to have a good experience with the clinician is extremely important to ensure that the patient wants to have a telehealth experience again in the future. This session will provide valuable information, practical use cases, and best practices for providers on how to provide professionalism throughout various telehealth interactions and situations.

We will walk through and discuss different situations within telehealth based on the audience. There are special considerations that have to be taken into account with each of the different delivery types that will be outlined. For each of the situations (video visit with a patient and caregiver(s), acute care (emergency) situation, or secure messaging) we will walk through how to prepare for the interaction to ensure the provider is well-prepared, how to set-up the environment around them, what considerations a provider should be cognizant of during an interaction, and how they should conclude the interaction. There are key items within each of these interactions that demonstrate why professionalism is important, and this session will highlight these items.

SPEAKERS: Bart Demaerschalk, MD (Mayo Clinic) and Megan Strole (Mayo Clinic)

Session Theme: This session focuses on how physicians and clinicians can use professionalism and web-side manner throughout their practice of telemedicine. Practitioner Primer

Key Learning Objectives:

1. Clinicians and practitioners will receive clinical use cases and real-life examples which will illustrate how to apply professional web-side manners in video telemedicine, acute care settings, and secure messaging.

2. Understand why professionalism is important within telemedicine and how it impacts the patient experience.

3. Apply the professionalism and etiquette that they have learned to their practice of telemedicine in the future and ensure patients have a good experience.

Key Actions for Participants to Implement:

1. Utilize information provided to apply professionalism into their current practice within telemedicine.

2. Understand how they can prepare for the digital interaction.

3. Understand how professionalism and web-side manners should impact the care they are providing to the patient.

Keywords: professionalism, web-side manner, etiquette

\section{ET-29}

\section{TELE-AAC: PROVIDING VOICE FOR VETERANS WITH ALS} AND MOVEMENT DISORDERS

Description: Approximately 4 million Americans, including children, cannot rely on their natural speech to meet their daily communication needs. Augmentative and alternative communication (AAC) systems can provide voice to persons with ALS and other movement disorders. Stephen Hawking, the late English theoretical physicist, is the most famous user of an AAC system. While Professor Hawking had access to both advanced AAC technology and specialized clinical expertise, many persons with debilitating neurologic disorders do not, hence the need for telehealth clinical and consultative models. Three presenters in a fast-paced 30-minute panel will describe the relatively recent and creative pairing of telehealth and augmentative and alternative communication (AAC): Tele-AAC.

First, Ellen R. Cohn, PhD, will provide an overview of Tele-AAC and potential uses by multi-disciplinary teams to serve vulnerable and disenfranchised populations across the lifespan.

Jenifer L. Juengling-Sudkamp, PhD will next detail how Tele-AAC use is providing voice for veterans with ALS and Movement Disorders. Over a two year period, tele-AAC has been deployed with 24 veterans in the Southeast Louisiana Veterans Health Care System, New Orleans, LA. The participating multi-disciplinary team consists of a neurologist, palliative care specialist, pulmonologist, respiratory therapist, physiatrist, registered dietitian, social worker, occupational therapist, physical therapist, and speech-language pathologist. 
In the final segment, Telina Caudill, MS, CCC-SLP, ATP will discuss the use of tele-AAC with approximately 50 patients, from VA to VA since 2012 and from VA to home since 2014, as well as her mentorship to establish the use of Tele-AAC in numerous VAs, nationally.

SPEAKERS: Ellen Cohn, PhD (University of Pittsburgh), Jenifer JuenglingSudkamp, PhD (Southeast Louisiana Veterans Health Care System/VA), Telina Caudill, MS, CCC-SLP (James A Haley VAMC, Polytrauma Rehab Assistive Technology Program)

Session Theme: Veterans (with application to: vulnerable and disenfranchised populations)

Key Learning Objectives:

At the conclusion of the session, participants will be able to:

1. Describe Tele-AAC.

2. Describe the applications for use of Tele-AAC in persons with degenerative neurologic conditions.

3. Describe how Tele-AAC improves access to medical care and quality of life for veterans with ALS and Movement Disorders.

Key Actions for Participants to Implement:

If practicing in a site with patients with ALS and movement disorders:

1. Assess the need for Tele-AAC in their site.

2. Consult with panelist mentors to establish or connect to Tele-AAC service delivery.

3. Refer patients with ALS and Movement Disorders with severe communication challenges to SLPs with Tele-AAC expertise.

Keywords: assistive and augmentative technology, Tele-AAC, ALS

\section{ET-30}

\section{THE NUDGE TOOLKIT: USING BEHAVIORAL ECONOMICS} IN TELEMEDICINE

Description: Nudges have been a popular tool as governments, nonprofits, and large corporations use insights from academia to change behavior in the real world. This session will translate the confusing scientific literature into practical virtual care applications. Participants will learn the evidence-based Nudge Toolkit that will enable them to leverage behavioral science to change patient behavior through telemedicine and virtual care channels. Three case studies will be presented that describe how One Medical has leveraged this toolkit to spark action on preventive care and quality measures, sustain patient engagement in virtual coaching programs, and shift patients to telemedicine services.

Detail for organizers: First, we will introduce practitioners to a practical framework for behavioral science as applied to virtual care - the Nudge Toolkit. Specifically, we will briefly cover five practical pillars of the Nudge Toolkit drawing on behavioral economics, marketing science, and behavior design, and introduce the concept of the nudge. We have a very simple articulation of the complicated literature that resonates strongly with clinicians, technologists, strategists, and other healthcare practitioners interested in driving behavior virtually. This is a Toolkit that participants will take home and use with their teams.

These evidence-based resources will be presented along with three short virtual care case studies based on the experiences of One Medical:

- Shifting patients to video visits and digital triage.

- Engaging patients in preventive care actions, such as flu vaccinations and lab orders.

- Sustaining patient enrollment in a virtual mental health coaching program.

We will also share best practices that help participants leverage this toolkit into their own organizations. A variant of this session was presented at the
Institute for Healthcare Improvement National Forum in December 2018. The topic was so popular that we were asked to present it twice on the keynote stage.

SPEAKERS: Paul Cohen (One Medical)

Session Theme: Tools and techniques for building innovation and engagement.

Key Learning Objectives:

1. Train interprofessional teams on the five key principles of behavioral science most relevant for virtual care.

2. Identify opportunities to use behavioral science to engage patients in virtual care without significant organizational resources.

3. Design a high-impact virtual care experiment that leverages practical insights from behavioral science to achieve business objectives.

Key Actions for Participants to Implement:

1. Educate others on behavioral science with the Nudge Toolkit.

2. Identify opportunities to use behavioral science to change behavior via telemedicine.

3. Run an experiment that significantly changes patient behavior via a virtual care channel.

Keywords: telemedicine nudges, how to increase video visit adoption, telemedicine behavior change

\section{ET-31}

\section{TRANSPARENCY, TRUST AND TELEHEALTH: THE PATIENT PERSPECTIVE}

Description: After the first iPhone was released in early 2007 we've had easy access to lots of information throughout every aspect of our lives. From that moment forward, patient experiences have been colored and shaped by a new culture of curiosity, sharing, and tools that make it possible for regular people to better understand and communicate more easily. But much of health information is still hidden, and still challenging to understand.

In this presentation, Liz Salmi will take you on a journey of how her own experience transformed her into a curious and engaged patient, will challenge assumptions about the capabilities of non-medical professionals, and introduce OpenNotes-the healthcare transparency movement that is driving improved communication between clinicians and patients.

Founded in research that started at the Beth Israel Deaconess Medical Center in Boston, OpenNotes encourages doctors and other healthcare professionals to share the notes they write with the patients they are caring for. Today, more than 180 health systems and organizations are sharing clinical notes with more than 36 million patients.

How will this kind of transparency impact the delivery of care in telemedicine? Research shows access to notes improves clinician/patient communication, improves patient adherence to care plans, and patients are able to find and correct errors in their records. Plain and simple: When patients can read their doctor's notes, they trust them more.

For an industry that wants to "know" patients through digital means, transparency initiatives like OpenNotes just might be telemedicine's new BFF.

SPEAKERS: Liz Salmi (OpenNotes, Beth Israel Deaconess Medical Center)

Session Theme: Trends and ideas that are driving the industry

Key Learning Objectives:

1. Define the healthcare transparency movement known as OpenNotes.

2. Analyze how patient access to clinical notes impacts telemedicine, including eConsults, due to diagnostic error.

3. Give examples of how OpenNotes is helping vulnerable populations (i.e., those who are seriously ill, living with chronic conditions, older adults) and their care partners. 


\section{EXPRESS TALK}

Key Actions for Participants to Implement:

1. Explain to colleagues what OpenNotes research is about.

2. Consider which side your organization wants to be on in the movement of health transparency.

3. Decide how your organization will provide health information to patients

Keywords: opennotes, patient experience, transparency

\section{ET-32}

\section{FDA'S NEW APPROACH TO DIGITAL HEALTH}

Description: FDA is proposing to change how it regulates software as a medical device (SaMD), which is medical software that meets the definition of device in the Federal Food, Drug, and Cosmetic Act. The hallmark of the change is a concept called Pre-Certification, in which FDA would permit marketing of certain software with minimal to no premarket review if software developers demonstrate to FDA that they have a culture of quality and organizational excellence. The proposed approach spans what FDA calls the total product lifecycle (TPLC) of a device, meaning there are premarket and post-market features, including a pre-market Excellence Appraisal and post-market tracking of product performance and safety. Session attendees will learn how FDA, through this proposed approach, would assure SaMD is safe and effective using a different regulatory model than what has been used for medical devices for the past $40+$ years. Session attendees will also hear of the political challenges FDA faces in advancing this approach.

\section{SPEAKERS: Aaron Josephson (ML Strategies)}

Session Theme: FDA's proposed paradigm shift for software oversight.

Key Learning Objectives:

At the end of the session, participants will be able to:

1. Explain how FDA's proposed regulatory model for software differs from the current regulatory model for medical devices.

2. Explain what FDA proposes to evaluate in determining whether to Pre-Certify a company, including explaining what an Excellence Appraisal is.

3. Explain the benefits and risks of FDA Pre-Certification, both as a program generally and why a company may want to pursue Pre-Certification specifically.

Key Actions for Participants to Implement:

1. Determine the applicability of FDA's proposed approach to their business plans.

2. Develop feedback for FDA on the merits and demerits of the proposed approach as it relates to products they make.

3. Implement changes to support a favorable excellence appraisal, if thinking to pursue pre-certification.

Keywords: digital health, regulatory, FDA, software, Pre-Certification

\section{ET-33}

REDUCING K-12 ABSENTEEISM WITH SCHOOL-BASED PEDIATRIC TELEHEALTH

Description: When children are healthy, they are better prepared to learn but approximately $21 \%$ of children in the United States live in families with incomes below the federal poverty level. Many of these children have in- adequate health insurance or limited access to healthcare practitioners, often relying on expensive ER visits.

With poor health linked to chronic absenteeism, high quality medical care is critical to improving outcomes in healthcare and education. When school districts in California implemented a virtual school-based clinic, available to every child, attendance rates improved significantly. Less than half of families in these districts reported having regular access to a primary care provider, and programs like these provide much-needed access to healthcare while reducing absence rates by up to $50 \%$ to give students more instructional hours in the classroom.

In this session, Robert Darzynkiewicz, a practicing physician and Chief Medical Officer at Hazel Health, will share how school-based telehealth can treat and help prevent some of the most common emergency ailments that represent $56 \%$ of avoidable ER visits. He will explore the best practices for successfully implementing a patient-centric clinical model that focuses on building relationships with school staff and families to support overall health. He will also discuss the correlation between health and attendance, and how implementing a virtual school-based clinic can help identify children who are at risk for chronic health issues so schools can provide preventative care.

Dr. Darzynkiewicz will describe the process for achieving 90\% enrollment, integrating with the school setting, establishing the training requirements and approach used for defining district health policies, creating customized care plans for a targeted population largely unaddressed in telehealth, and protocol for referrals and sharing discharge information.

SPEAKERS: Robert Darzynkiewicz, MD (Hazel Health) and Rose Bomentre (San Bernardino City Unified School District)

Session Theme: A school-based K-12 telehealth program, beginning with underserved populations, can increase access to healthcare and improve attendance, giving children a better chance at academic success.

Key Learning Objectives:

1. Establish best practices for implementing a virtual school-based clinic that provides children with free and convenient access to healthcare services to address minor urgent care issues.

2. Understand the importance of care coordination using a multidisciplinary team of school nurses, administrators, physicians, nurse practitioners and primary care providers.

3. Analyze results to demonstrate how virtual clinics can affect the correlation between health and attendance, in order to identify children at risk for health-related absences and mitigating these causes.

Key Actions for Participants to Implement:

1. Establish best practices for implementing a virtual school-based clinic, and which audiences benefit most.

2. Develop a multidisciplinary team for care coordination.

3. Identify children with chronic health issues at risk for being absent from school.

Keywords: school, pediatric, attendance

\section{ET-34}

\section{HOW TO INFLUENCE TELEHEALTH POLICY AT THE STATE LEVEL}

Description: State telehealth laws are fluid. The Washington State Telehealth Collaborative was formed through legislation in 2016 to provide a forum to improve the health of Washington residents through the collaboration and increasing public awareness of telehealth as a delivery mechanism. The Collaborative has a membership comprised of a wide-range of stakeholders, with various provider and health systems represented, payers, state legislators, and 
others. This variation in membership to ensure multiple perspectives are represented during policy-making discussions is critical to the success of influencing change at the state level. The state legislature looks to the Collaborative to advise on legislative changes to advance telehealth with the goal of increasing access to care.

Washington has several laws related to telehealth, including coverage parity for private payers and Medicaid, and defining telehealth. Participants in this session will learn how to find and assess current state laws to determine where language enhancements may be made to expand telehealth offerings. Some laws have unintentional operational consequences and can be edited to achieve the original spirit of the law. For example, the Collaborative reviewed the Washington law related to store and forward reimbursement by third-party payers. To be reimbursed for clinical services delivered through the store and forward telehealth modality, per Washington law there must be an associated office visit between the client and the referring healthcare provider. The requirement for an associated office visit between the client and the referring healthcare provider inhibits clinicians offering store and forward services. The Collaborative recommended removing this requirement for reimbursement from existing law.

In 2018, the Collaborative focused on three areas: 1) training providers on telemedicine; 2) cost-effectiveness of telemedicine; and 3) payment parity. This session will identify key sides of the discussion for each area and discuss the outcomes for telehealth laws in Washington.

SPEAKERS: Sarah Orth (Seattle Children's Hospital)

Session Theme: Trends and ideas that are driving the industry

Key Learning Objectives:

1. Upon completion, participants will be able to identify the key stakeholders to be involved in discussions to influence state policy and how to engage them with an example of the Washington State Telehealth Collaborative, and describe the role of law and government in promoting and protecting telehealth through policy.

2. By the end of the presentation, participants will know how to identify key current state laws and policies regarding telehealth, understand how to assess their impact on clinical service delivery, and define gaps in law and policy that need to be addressed to decrease barriers to offering clinical services through telehealth.

3. Upon completion, participants will be informed of telehealth policy and law discussions of the Washington State Telehealth Collaborative, proposed changes to reimbursement and parity laws, development of a state telehealth provider training guide, and how to advocate for the importance of smooth telehealth operations though policy.

Key Actions for Participants to Implement:

1. Define key stakeholders to be involved in discussions to influence state policy.

2. Find state laws, assess their operational impact, and propose edits to remove barriers.

3. Advocate for the importance of smooth telehealth operations though policy.

Keywords: state law parity

\section{ET-35}

\section{TRAINING MEDICAL VIRTUALISTS: NUISANCE OR NECESSITY?}

Description: The telemedicine experience for pediatric and adolescent patients is changing as technology and high-speed internet becomes more ubiquitous and integrated into daily life. Subsequently, more patients, families, and providers are expecting similar conveniences from their healthcare experience, and are increasingly comfortable with a virtual care experience. Yet virtual care is not a one-size-fits-all model, a notion which is particularly true in vulnerable populations and those seeking mental healthcare. The professional medical virtualist understands these unique considerations, and adeptly applies them in the appropriate scenarios. This advanced communication skill is being taught in some medical schools, nursing schools, and training programs; yet formal training and privileging of telemedicine practitioners is neither consistent nor required throughout the industry at this time.

This session will present a framework for training medical virtualist, with an emphasis on unique considerations for providing virtual care to vulnerable populations. We will share experiences of two children's hospitals which differ in culture, reimbursement, and regulations related to provision of virtual care to children and adolescents, and highlight how those drivers impact the delivery of virtual care. We will discuss the journey in making privileging a requirement, and review obstacles from the perspectives of other organizations who have intentionally chosen not to require privileging. We will summarize current regulations, recommendations, and available resources for training. We will discuss successes and pitfalls, what to anticipate in the training process, as well as provide examples of a multimodal approach to a telehealth training curriculum anchored in adult learning theories (e.g. experiential learning, interactive techniques, and simulation-based sessions).

SPEAKERS: Mark Lo, MD (Seattle Children's Hospital) and Dana Schinasi, MD (Ann \& Robert H. Lurie Children's Hospital of Chicago)

Session Theme: Practitioner Primer

Key Learning Objectives:

1. Understand why formalized telehealth training is important for practitioners who seek to become a professional medical virtualist.

2. Describe key attributes and strategies of a medical virtualist who engages with vulnerable populations.

3. Gain tools to develop a training program for telehealth practitioners.

Key Actions for Participants to Implement:

1. Understand the broader case for requiring formalized training of practitioners in virtual care.

2. Integrate the unique skills that are required in providing virtual care to vulnerable populations.

3. Gain tools to develop a formalized training program for medical virtualists.

Keywords: pediatrics, privileging, training

\section{ET-36}

OVERVIEW OF PHYSICIAN WELLBEING - THE PROBLEM, TECHNOLOGICAL CAUSES AND POTENTIAL SOLUTIONS

Description: Three academic past presidents of ATA, all physicians with differing specialty expertise (Psychiatry, Pediatrics and Pulmonary/Critical Care), will present their perspectives on how the use of telemedicine technologies and workflows can improve clinician resilience and reduce burnout and what their respective institutions are doing to improve provider wellness. They will describe how this then improves the quality of care for all their patients, especially in environments where virtual health technologies are integrated into traditional health systems.

SPEAKERS: Peter Yellowlees, MD (UC Davis Department of Psychiatry) 


\section{EXPRESS TALK}

\section{ET-37}

\section{PEDIATRICS, TECHNOLOGY AND CLINICIAN WELLBEING}

Description: Three academic past presidents of ATA, all physicians with differing specialty expertise (Psychiatry, Pediatrics and Pulmonary/Critical Care), will present their perspectives on how the use of telemedicine technologies and workflows can improve clinician resilience and reduce burnout and what their respective institutions are doing to improve provider wellness. They will describe how this then improves the quality of care for all their patients, especially in environments where virtual health technologies are integrated into traditional health systems.

SPEAKERS: Dale Alverson, MD (University of New Mexico School of Medicine)

\section{ET-38}

\section{THE ROLE OF TECHNOLOGY IN THE MILITARY, AND ITS IMPACT ON PROVIDER WELLBEING}

Description: Three academic past presidents of ATA, all physicians with differing specialty expertise (Psychiatry, Pediatrics and Pulmonary/Critical Care), will present their perspectives on how the use of telemedicine technologies and workflows can improve clinician resilience and reduce burnout and what their respective institutions are doing to improve provider wellness. They will describe how this then improves the quality of care for all their patients, especially in environments where virtual health technologies are integrated into traditional health systems.

SPEAKERS: Ron Poropatich, MD (Health Sciences and Professor of Medicine, Division of Pulmonary, Allergy, and Critical Care Medicine, University of Pittsburgh)

\section{ET-39}

\section{HEAR FROM KAISER PERMANENTE AND HOW THEY ADDRESS BURNOUT AND WELLBEING}

Description: Dr. Parikh will share insights on how Kaiser Permanente has embedded telemedicine within their clinical workflows. Hear about their lessons learned, key considerations across patient populations, and resulting outcomes on both clinician burnout and overall improvement of quality of care for all patients.

SPEAKERS: Rahul Parikh, MD (Kaiser Permanente)

\section{ET-40}

\section{WHAT PRACTICAL STEPS INVOLVING TECHNOLOGY CAN} BE TAKEN TO MITIGATE BURNOUT?

Description: Three academic past presidents of ATA, all physicians with differing specialty expertise (Psychiatry, Pediatrics and Pulmonary/Critical Care), will present their perspectives on how the use of telemedicine technologies and workflows can improve clinician resilience and reduce burnout and what their respective institutions are doing to improve provider wellness. They will describe how this then improves the quality of care for all their patients, especially in environments where virtual health technologies are integrated into traditional health systems.

SPEAKERS: Ron Poropatich, MD (Health Sciences and Professor of Medicine, Division of Pulmonary, Allergy, and Critical Care Medicine, University of Pittsburgh); Dale Alverson, MD (University of New Mexico School of Medicine); Peter Yellowlees, MD (UC Davis Department of Psychiatry) and Rahul Parikh, MD (Pediatrics Walnut Creek Medical Center)

\section{ET-41}

\section{THE ETHICS AND REGULATIONS OF AI}

Description: Artificial intelligence (AI) and telehealth are expected to improve diagnostic accuracy and decrease costs. The use of $\mathrm{AI}$ is rapidly expanding and its applications are penetrating into medical practice, raising questions around responsible regulation and the ethical considerations to allow us to use this powerful technology wisely. This panel discussion will explore the framework of the current regulatory issues and outline the ethical issues raised by the use of AI in healthcare. Participants will learn how artificial intelligence is changing the standards for medical practice and licensure.

SPEAKERS: Sarv TerKonda, MD (Mayo Clinic) and William Cheshire, MD (Mayo Clinic)

Key Learning Objectives:

1. Understand the application and challenges of artificial intelligence in healthcare.

2. Review the current and future regulatory framework surrounding artificial intelligence.

3. Identify the ethical considerations of artificial intelligence in healthcare.

\section{ET-42}

\section{INNOVATION CENTERS - FROM IDEAS TO IMPLEMENTATION: HOW DID THEY DO IT?}

Description: Healthcare delivery organizations are actively piloting new technologies and testing new models within dedicated innovation centers. To support engagement, improve efficiency, and realize scale, many of these initiatives sit on a digital foundation. During this session, innovation leaders drawn from across the healthcare ecosystem will discuss what they're prioritizing, what's demonstrating the most promise, and how they are working to implement program successes system-wide.

SPEAKERS: Randall Moore, MD (Medical Excellence Inc); Martin Doefler, MD (Northwell); and Kelly Rhone, MD (Avera eCARE)

\section{ET-43}

\section{RPM BENEFITS POPULATION HEALTH EFFORTS}

Description: Patient engagement is critical to realizing outcomes and improvements necessary for healthcare systems' movement toward valuebased care. However, the hardest populations are often those with the most obstacles to the kind of engagement needed to make a positive impact on their care and on costs. Telemedicine, once thought of as a fringe approach 
appropriate for only a small population of total patients, is now being used to significantly boost engagement among patients with chronic and costly morbidities such as congestive heart failure (CHF) and chronic obstructive pulmonary disease (COPD), along with specialized but typically very costly populations such as those with post-partum hypertension. The University of Pittsburgh Medical Center (UPMC) and the Ontario Telemedicine Network (OTN) are both influential champions for the use of telemedicine to help manage these patient populations and will discuss how their use of this platform is improving care and lowering costs.

SPEAKERS: Andrew Watson, MD (UPMC) and Laurie Poole (Ontario Telemedicine Network)

Key Learning Objectives:

1. Demonstrate how UPMC and OTN utilized remote patient monitoring to improve patient engagement and outcomes for chronic disease management.

2. Analyze the approach taken to ensure implementation of remote care technology.

3. Discuss how remote care succeeds in inspiring patient engagement where other approaches fall short

\section{ET-44}

\section{CHALLENGES OF EDUCATING THE NEXT GENERATION} OF CLINICIANS IN TELEHEALTH

Description: Telehealth has revolutionized the delivery of healthcare for the next generation of consumers. While there are many resources for training clinicians in telehealth, full-scale integration of telehealth education has lagged behind in healthcare professional training programs. This session will describe the work being done at Yale University and the US Department of Veterans Affairs to integrate a telehealth curriculum into the medical and associated health training programs. Educational resources have been developed to integrate store and forward, clinical videoconferencing, and now mobile video into existing training programs. The session will describe best practices in developing strategic plans for telehealth training for medical residents, psychology trainees, nursing professional trainees, speech pathology trainees, etc. Specific didactic sessions will be described along with a discussion of simulated patient experiences. Challenges, including limitations imposed by accrediting bodies and state training licenses will be discussed. Ultimately, effective integration of telehealth education into existing training programs for the next generation of healthcare professionals is essential for optimal success and continued expansion of telehealth.

SPEAKERS: Linda Godleski, MD (VA)

Session Theme: Integration of telehealth education in multi-discipline health professional training programs is essential for the next generation of clinicians.

\section{Key Learning Objectives:}

1. Participants will understand the unique challenges of educating healthcare professional trainees in telehealth, e.g. educational accreditation and state requirements.

2. Participants will learn how to access educational resources for their trainees.

3. Participants will develop strategic plans for integrating telehealth education into training programs for the next generation of healthcare professional trainees.

Key Actions for Participants to Implement:
1. Could invite trainees to shadow their telehealth experiences.

2. Could access didactic and simulated patient teaching materials for their trainees.

3. Could develop a strategic plan for expanding telehealth education into medical and associated health training programs.

Keywords: education, academia, trainees

\section{ET-45}

\section{ARE RETAILERS THE FUTURE OF HEALTHCARE?}

Description: Retail outlets like Walmart and Amazon have announced plans to more aggressively compete in the healthcare industry. The healthcare sector continues to undergo significant transformation with mergers and acquisitions like CVS-Aetna and Cigna-Express Scripts, creating new opportunities for patients to access care and receive healthcare services. As these organizations seek to provide convenient and affordable access to care, telehealth will play a significant role in the competition for market share and will create new opportunities for innovation. Additionally, the increasing adoption of telehealth by retail outlets and vertically-integrated healthcare organizations raises new policy questions in such areas as information access, privacy and security, and the convergence of health and consumer data. Current policies are insufficient to address the unique issues created by these new developments. Policies need to be reimagined in order to guide telehealth innovation toward responsible, value-driven care for patients and the healthcare system.

SPEAKERS: Keisuke Nakagawa, MD (UC Davis Health)

Session Theme: Trends and ideas that are driving the industry

Key Learning Objectives:

1. Retail outlets are offering innovative models of care using telemedicine by leveraging their physical and digital retail infrastructure, technological expertise, and consumer-driven business focus.

2. Recent mergers and acquisitions are quickly changing the healthcare landscape and creating opportunities for more telehealth innovation and access.

3. Significant policy issues need to be addressed including retail outlets gaining access to healthcare data as telehealth providers.

Key Actions for Participants to Implement:

1. Serve as knowledge leaders in their organization on key policy issues related to telehealth.

2. Incorporate the potential impact of retailers using telehealth on their practices/business into strategic planning.

3. Advocate for responsible data and technological implementation related to telehealth

Keywords: retail, Amazon, Walmart

\section{ET-46}

\section{TELEMEDICINE AS PART OF A HIGH PERFORMANCE RURAL HEALTH SYSTEM}

Description: The Helmsley Charitable Trust is a large funder of telemedicine provision in seven states of the Upper Midwest. Through the Rural Healthcare Program of Helmsley, 167 of 362 Critical Access Hospitals in the region now have access to Pharmacists and Board-Certified emergency physicians and critical care-trained and experienced RN's via telemedicine. Through work 


\section{EXPRESS TALK}

with small rural hospitals, telemedicine, and the RUPRI (Rural Policy Research Institute, University of Iowa) Health Panel, we've also discovered that telemedicine is a vital component of transitioning to or creating a High Performance Rural Health System. Several RUPRI papers since 2011 have discussed this concept, laid out the components, and given case studies and policy considerations. Helmsley Rural Healthcare Program staff have had the unique experience of seeing telemedicine in action and how it not only improves access, but decreases isolation of providers and adds a collegial approach to rural medicine. Walk through a bit of rural healthcare history and discover the intersection of telemedicine and the evolution towards a High Performance Rural Health System.

\section{SPEAKERS: Heidi Schultz (The Helmsley Charitable Trust)}

Session Theme: Telemedicine is a useful tool for many rural health systems, and an integral part of a High Performance Rural Health System

Key Learning Objectives:

1. The theory/model of The High Performance Rural Health System.

2. Components and necessary ingredients of a High Performance Rural Health System.

3. How telemedicine can and does provide a necessary component of a High Performance Rural Health System.

Key Actions for Participants to Implement:

1. Self-audit components of own health system that exist or are absent of a High Performance Health System.

2. Discuss concept with administrators, board, and community members to begin community/stakeholder buy-in.

3. Assess current use of telemedicine and/or Health Information Technology and plan for improvements.

Keywords: rural, funder, rural telemedicine, critical access hospitals

\section{ET-47}

THE OPIOID CRISIS: THE NEW LEGISLATION, POLICY, AND WHERE TELEMEDICINE FITS IN

Description: The opioid epidemic is now one of America's deadliest drug overdose crises. According to the CDC, 130 Americans die every day from an opioid overdose. Towards the end of 2018, Congress, with bipartisan support, passed the Support of Patients and Communities Act which comprehensively addresses the crisis. For telemedicine advocates, there was some good news in that the Act requires the DEA to implement special registration rules under the Ryan Haight Act. Probably the best news in the SUPPORT ACT was the legislation sponsored by Rep. Doris Matsui (D-CA) which removed the geographic distinction and qualifications for an originating site for Medicare beneficiaries for the treatment of substance abuse. Those restrictions are not removed until 2020 so what can telehealth do until then?

This one-hour presentation will include Mohana Ravindranath from POLITICO who writes on telehealth policy, Janelle Wesloh from Hazelden Betty Ford, and a representative from Rep. Matsui's office is invited. WE are also going to invite a provider in the Medicaid/Medicare space to round out the panel. Tania Malik, Chair of the TMG SIG, will moderate the panel.

The presentation will include a look at how the legislation was passed, what it really means, what the possibilities are for enhanced legislation, the policy around telehealth legislation, and the practical effects of telemedicine use for this crisis.
SPEAKERS: Tania Malik (Mindcare Solutions) and Janelle Wesloh (Hazelden Betty Ford Foundation)

Session Theme: New legislation passed at the end of 2018 that provided support and solutions to combat the opioid crisis. Emphasis on telemedicine solutions.

Key Learning Objectives:

1. The current state of the opioid crisis today.

2. Understand the current legislation and proposed legislation.

3. Have a behind the scenes look at policy for SA.

4. Learn what telemedicine pilots are happening with different degrees of success

Key Actions for Participants to Implement:

1. Where they can help to promote legislation that uses telemedicine to combat the crisis.

2. Implement telemedicine within the legal framework.

3. Understand the success and failures of various pilots.

Keywords: opioid abuse, legislative policy, SUPPORT Act

\section{ET-48}

\section{SYMPTOM SPECIFIC CARE AND THE GOAL TO PROVIDE PERSONALIZED} AND PATIENT CENTERED HEALTHCARE

Description: Ro is a direct-to-consumer telehealth company that handles everything from diagnosis to convenient delivery of medication. 70\% of our patients are treated via asynchronous telemedicine and we're live in 45 states, able to provide care to $98.5 \%$ of the US population. Ro has two verticals: Roman (tackling men's health) and Zero (tackling addiction). Roman started by treating erectile dysfunction and now treats 5 conditions. Zero is a comprehensive program that combines prescription medication, nicotine replacement therapy and support via our app to help people quit smoking. Ro will soon launch an end to end vertical for women.

As a healthcare technology company, we built an EMR to help our physicians provide quality and safe care efficiently and effectively. Our technology and data analytics optimize our physician workflow and member experience. By providing disease-specific care, we can personalize our virtual visits to cover all information needed to safely prescribe medication to our members.

The majority of our physicians work full-time in traditional practice settings but can provide care and support to our members because of our symptom-specific model. Our physicians feel supported and comfortable prescribing medication via telemedicine because of our thorough online visits, extensive protocols and treatment plans that allow much more extensive counseling than an office setting. By knowing what symptom the patient is seeking care for ahead of time, we can design a personalized experience. Our platform and pharmacy integration, allows us to discreetly deliver medication to our members without the burden of having to go to the pharmacy. Our extensive treatment plans educate our members, both about their condition, and its potential underlying causes. Our motto is to meet our members at eye level. We are here to take on the complexity of healthcare so that our members feel better and build the lives they want.

SPEAKERS: Melynda Barnes, MD (Ro)

Session Theme: New frontiers and emerging best practices in the application of telehealth and tools and techniques for building innovation and engagement.

Key Learning Objectives: 
1. How building an end-to-end company leads to patient-centered care Integration of pharmacy and physician platform allows for two important stakeholders to work together to focus on patient needs while providing quality and value.

2. Pros and Cons of asynchronous telemedicine - Pros: convenience for patient and physician, ease of physician workflow management, increased accessibility for patients - Cons: harder to develop patient-physician relationship; can feel impersonal; some confusion amongst patients as to whether a doctor or an algorithm is making treatment decisions.

3. How symptom-specific virtual visits can improve the healthcare experience for patients and physicians -Patients can find education and treatment for the symptom that is bothering them at that time -Physicians know ahead of time what is their patient's chief complaint and Virtual Visit can be specifically designed for each symptom

Key Actions for Participants to Implement:

1. Evaluate the use of asynchronous telemedicine to provide care to patients.

2. Incorporate data analytics into improving the patient experience

3. Incorporate patient-centered design into patient and physician workflow.

Keywords: asynchronous telemedicine, healthcare technology, personalized healthcare

\section{ET-49}

\section{BUILDING TRUST WHILE CRYING WITH STRANGERS}

Description: A talk on empathy from a father who has never heard his son speak. Practical lessons about the power of empathy to solve telemedicine problems. Mulligan uses his stories from years co-designing with low income communities, teaching high schoolers how to interview terminally ill youngsters, designing ethnographic field research for business, and connecting with his nonverbal son through lines from musicals. He juxtaposes the unique needs of telehealth practitioners against personal experiences coaching low-income pregnant women to quit smoking. (Each requires us to foster sincere and often surprising trust.)

SPEAKERS: Ryan Mulligan (Nason Group)

Key Learning Objectives:

1. How empathy plays a role in framing the right problem Building solutions through intense listening.

2. Rethinking empathy in simple, down to earth ways.

3. Connecting to individuals with low levels of trust through screens.

4.

\section{ET-50}

\section{CREATING A CULTURE OF INNOVATION}

Description: A conversation with two innovators in healthcare who believe it's long overdue for some good old fashioned disruption. We will cover a range of topics around what we have experienced firsthand what it takes to be successful in standing up and sustaining innovation in healthcare.

SPEAKERS: Julie Reisetter (Ascension); Robin Glasco (Bamb Global Healthcare Consulting \& Investments); and Christopher Northam (HCA Healthcare)
Session Theme: How to instill an innovative culture in an existing organization How not to get fired for doing what you were hired to do How to gain traction and momentum.

Key Actions for Participants to Implement:

If you want the innovator starter pack, this is the session for you! Learn (1) about mindsets and its value, (2) key ingredients for success, and (3) what to stop doing

Keywords: disruptors, mavericks, badassery

\section{ET-51}

\section{DEVELOPING OUR OWN TELEHEALTH TO IMPROVE PATIENT CARE}

Description: Telemedicine is the fastest growing segment in healthcare. A new healthcare delivery model, it can provide significant value to patients and reshape the healthcare system. With the advent of digital health innovation, we have an abundance of opportunities to innovate, modernize, and improve patient health.

At Beth Israel Deaconess Medical Center and the Health Technology Innovative Center, we are consistently aiming to innovate for the betterment of our patients. Through our unique synchronous, asynchronous, and remote monitoring modalities, we are able to best provide a valuable experience to patients.

SPEAKERS: Oren Mechanic, MD (Beth Israel Deaconess Medical Center)

Key Learning Objectives:

1. Investigate the Opportunities for Value-based Care.

2. Showcase unique telehealth/digital health systems.

3. Invoke a disruptive innovative mindset to healthcare.

Key Actions for Participants to Implement:

1. Academic Medical Center

2. Value-Driven Healthcare

3. Digital Health Innovation

\section{ET-52}

\section{INVESTING IN TELEHEALTH - WHAT'S NEXT?}

Description: As the telehealth industry evolves and matures, what will be the opportunities for investors going forward? The panelists will discuss the trends shaping the telehealth investment landscape the companies that exemplify those trends, and the potential for M\&A activity and other exits in the space.

SPEAKERS: Indu Subaiya, MD (Health 2.0, HIMSS); Jon Gordon (New YorkPresbyterian); and Emma Cartmell (Cartmell LLC)

Session Theme: Investment

Key Actions for Participants to Implement:
1. Venture capital
2. Investment
3. Financing
4. Telehealth
5. VC
6. Private equity 


\section{EXPRESS TALK}

\section{ET-53}

\section{SEEING AROUND CORNERS: HOW WE GOT HERE...AND WHERE WE'RE GOING}

Description: It's hard to believe that just two decades ago, what we now call connected health was in its infancy. We've learned, grown, succeeded and failed. We now have technologies available that were never even dreamed of just 10 years ago, and a convergence of market dynamics that make connected health solutions a prime driver in changing healthcare delivery, wellness and prevention.

Dr. Joe Kvedar has been a leading architect of connected health, imagining the future - and then helping to invent it. Join him and a hand-picked group of thought leaders, as they explore what the next decade will look like, to help you 'see around corners' and prepare for the future.

SPEAKERS: Joseph Kvedar, MD (Partners HealthCare, Connected Health)

\section{ET-54}

\section{HOW TELEHEALTH MIGHT RESHAPE THE FUTURE OF HEALTHCARE}

Description: U.S. Healthcare will soon be a $\$ 3$ trillion industry with a $\$ 4$ trillion price tag. Most of those dollars will be spent to treat the acute care needs of patients with chronic conditions. Telehealth and related digitaltechnology capabilities are typically used as tools for faster, better and cheaper improvements to the current system. Given the more than $\$ 1$ trillion wasted each year on failures in care delivery and coordination, fraud, abuse, administrative complexity and so on, that's critically important. The next decade will also offer immense opportunities to leverage Telehealth to fashion business models that facilitate and accelerate the realignment of healthcare to better address chronic disease prevention and care.

SPEAKERS: Chunka Mui (Devil's Advocate Group)

\section{ET-55}

\section{ADDRESSING THE SUPPLY AND DEMAND MISMATCH}

Description: Startups on the cutting edge are helping to design a future of health and wellness that is built on imagination, ingenuity and emerging technologies. Explore the novel applications, new platforms and consumer-driven models that will help to address the growing gap in supply versus demand, and the opportunities and challenges ahead.

SPEAKERS: Kristen Valdes (b.wel); Julia Hu (Lark); Victor Wang (care.coach); and Chunka Mui (Devil's Advocate Group)

\section{ET-56}

\section{COMMITMENT TO CONNECTED HEALTH: DRIVING STRATEGY AND EXECUTION AT PROVIDER ORGANIZATIONS}

Description: More than just a shot in the dark, large provider organizations are betting on telehealth to solve many of our biggest challenges in care delivery. Learn how a commitment to technology-enabled care is fitting in to the broader strategy and enabling the implementation of telehealth solutions, the lessons learned and near-term goals for front-line providers.
SPEAKERS: Laurie McGraw (American Medical Association); Scott Shipman, MD, MPH (AAMC); Heather Meyers (Boston Children's Hospital)

\section{ET-57}

\section{BREAKING HEALTH INERTIA: UPTAKE, ACTIVATION \& ENGAGEMENT}

Description: Today's healthcare consumer faces a mind-numbing array of decisions as they navigate the complexities of how, when and where medical care is delivered. It's no surprise the result is often apathy and disengagement...the dilemma of health inertia: getting people to face personal health challenges, adhere to a plan of action, and stay motivated to proactively deal with their health.

Telehealth is no different. Activating new customers, from uptake to activation to participation to engagement, means braking health inertia.

This session will presents findings from a national health inertia study that reveals industry efforts to educate people about conditions, products and brands is not motivating them to take meaningful steps to improve their health. In contrast, the research demonstrates that personalized content that zeroes in on real people, including their deep- seated motivations and emotional triggers-especially fear and hope-inspires action and stimulates thoughtfulness by double to triple traditional efforts.

SPEAKERS: Destry Sulke, MD (Wunderman Health)

\section{ET-58}

\section{THINGS ARE NOT ALWAYS AS THEY APPEAR}

Description: We're seeing an unprecedented number of new businesses, business models and devices in healthcare. It is an exciting time and at one level, it gives us confidence that we can do more good for more people, leveraging technology and methods. We love tracking our health stats and we appreciate having clinicians who help us manage our disease. But is that the end game? If we take some ideas a bit further, we might have a deeper understanding of what these companies really want to achieve. It's complicated and often quite sophisticated.

SPEAKERS: Donald Jones (Cardiff Ocean Group) and Ron Dixon, MD (Onduo)

Key Learning Objectives:

1. Gain better understanding of the business model behind new market entrants.

2. Understand what can constitute "true competitive advantage".

3. Have a more discerning view as you evaluate business opportunities for your organization.

\section{ET-59}

\section{VIRTUAL CARE TAKES CENTER STAGE FOR HEALTH PLANS}

Description: What do health insurance providers really think about virtual care? America's Health Insurance Plans (AHIP), gathered the views and insights as part of their first, and the most comprehensive survey to date, across types of services and lines of business, which was funded by Teladoc Health, Inc. as part of AHIP's Sponsored Research Program. 
We've officially entered the era of the "virtual front door." During this webinar, we'll share findings from the most comprehensive survey to date about health plans' perceptions of virtual care. This survey, reveals how health plans are prioritizing virtual care and where comprehensive offerings are expanding. We'll share key motivators and emerging use cases, the most commonly implemented services and where value is being realized across various areas of the health plan business to control costs and improve outcomes with a virtual first strategy.

SPEAKERS: Kate Berry (America's Health Insurance Plans (AHIP)) and Dan Trencher (Teladoc Health)

\section{Key Learning Objectives:}

1. Understand where health plans are investing in virtual care today, and where they are growing their offerings.
2. Learn about "bright spots" where virtual care is providing value across lines of business, including ASO, Medicaid Managed Care, and Medicare.

3. Hear "lessons learned" along the way from health plan survey participants

Key Actions for Participants to Implement:

1. Guide decisions about where to invest in virtual care to improve outcomes, while managing costs in today's healthcare environment.

2. Raise awareness about the value of virtual care in 5 key areas of the business, including value-based care.

3. Share virtual care benefits with your provider network.

Keywords: AHIP Virtual Care Survey Virtual care for health plans Health plans implementing virtual care 


\section{Roundtable Discussion}

\section{RD-60}

\section{DISASTER MEDICAL RESPONSE: WHAT A CITY HAS LEARNED AND HOW TELEMEDICINE CAN IMPROVE MEDICAL CARE DURING AN EMERGENCY}

Description: In this panel discussion format, leaders in disaster response from the City of New Orleans will discuss the role of telemedicine in disaster medical response, the history of telehealth use in disasters, and the future of how telemedicine can augment response to natural and manmade disasters.

SPEAKERS: James Aiken, MD (LSU Emergency Medicine); Sarah Babcock, MD (City of New Orleans); Meghan Maslanka, MD (LSU Disaster Medicine); Stephen Murphy, PhD, MPH, MBA (Tulane School of Public Health); and Jeffrey Edler, MD (LSU Emergency Medicine)

Key Learning Objectives:

1. Review the history of telemedicine in disasters.

2. Learn how telemedicine can improve the reach of medical providers during disaster response.

3. Discuss the future of telemedicine in disaster medical response.

\section{RD-61}

INNOVATING, ACCELERATING AND FUNDING: THE FUTURE OF DIGITAL HEALTH

Description: Healthcare's 'innovation index' is off the charts. The variety and velocity of digital and tele health solutions sweeping across the healthcare landscape is unprecedented as they seek to reduce health expenditures, improve access to care, manage chronic conditions, and extend life expectancy. Both startups and established companies alike are seeking to leverage technology to empower consumers. Investment surged in 2018, as innovators are breaking down barriers with wearables, blockchain, artificial intelligence (AI), 'Big Data', Internet of Things, augmented and virtual reality, voice technology, and precision medicine.

This session will bring together leaders offering three distinct perspectives looking at digital and tele health: AVIA, leading a network of health systems working together to innovate and transform markets; 7wire, an early stage healthcare venture fund, and; ARDA Health, an AI-based virtual health coaching fitness platform tied to wearables.

SPEAKERS: Derek Baird (Avia), Lindsay Resnick (Wunderman Health), Mark Agnew (Step Health), Alyssa Jaffee (7wire)

Key Learning Objectives:

As believers in 'innovating with a purpose' the session will explore:

1. Value of health incubators and accelerators in digital health

2. Investment assessment 'tricks of the trade' the 'shark tank' questions

3. Pros and cons of corporate v VC funding

4. 'Managing Up, Down or Sideways' investor relations

5. Futurist look at digital and tele health

\section{RD-62}

\section{TELEHEALTH ACROSS A WOMAN'S LIFESPAN}

Description: Women are often considered the Chief Medical Officer of the home, and thus may be the key for patient engagement and optimal patient experience, providing unique opportunities for telehealth. Panelists will address how telehealth can be applicable across women's life course, across specialties and integrated across the delivery system. They will discuss best practices and include information about how women use healthcare today, how this translates to telehealth and how women will continue to use healthcare in the future, making women's health not just an option, but an imperative when expanding service delivery models of care including telehealth.

SPEAKER: Emily Stewart (Planned Parenthood Federation of America), Laurie Zephyrin, MD (The Commonwealth Fund), Sylvia Romm, MD (American Well)

Session Theme: Women's health, including reproductive health.

Key Learning Objectives:

1. Understand the need to address health across women's life course, across specialties and integrated throughout the delivery system.

2. How best to engage with women as the social drivers of healthcare, creating business opportunities while keeping the patients at the center of care.

3. Best practices for telehealth to address the unique needs of women.

Three Key Actions for Participants to Implement:

1. Address health across women's life course, across specialties, integrated throughout the delivery system.

2. Engage with women as the social drivers of healthcare.

3. Implement best practices for telehealth to address the unique needs of women.

Keywords: women, healthcare, innovation

\section{RD-63}

\section{DIGITAL HEALTH AND FDA'S EFFORTS TO ENCOURAGE} TECHNOLOGY INNOVATION

Description: From mobile medical applications and digital therapeutics to advanced analytics and AI, digital health products make up a rapidly expanding portion of the medical device economy. While these products hold tremendous potential, the question of their oversight has challenged regulators, including the U.S. Food and Drug Administration ("FDA"). This session will discuss how the digital health sector is evolving and how it has been impacted by recent regulatory developments, including efforts by Congress and FDA to encourage digital health product innovation. The course will also discuss the practical and legal challenges that industry must navigate as new technologies are developed and integrated into an already changing healthcare system. 


\section{ROUNDTABLE DISCUSSION}

*Please note that we are still considering who should join as additional speakers, but are currently thinking about someone from InTouch Health, Astellas Pharma, and/or Akili Interactive.

SPEAKERS: Ian Pearson, JD (Jones Day); Emre Gulturk (Akili Interactive); Bryan Anderson, JD (Astellas); Joe DeVivo (InTouch Health)

Session Theme: This session will focus on new digital technologies and how these products are defined and regulated from an FDA perspective.

\section{Key Learning Objectives:}

1. Participants will better understand the types of products/technology that may require FDA oversight from a jurisdictional perspective, such as clinical decision support software, digital therapeutics, peripheral devices used in combination with telehealth carts, etc.

2. Participants will learn about the various marketing pathways for FDAregulated digital products and the types of data/information required for marketing authorization.

3. Participants will gain a broad understanding of current regulatory trends that are shaping the development of novel digital products, and practical methods for applying these trends from an industry perspective.

Three Key Actions for Participants to Implement:

1. Development of SOPs designed to ensure products don't inadvertently cross into FDA's regulatory purview.

2. Participants will gain a strong foundation for understanding how FDA thinks about and regulates digital products.

3. An understanding of how digital technology can be integrated into telehealth platforms.

Keywords: digital health; FDA; precision medicine; digital therapeutics; clinical decision support; software precertification

\section{RD-64}

\section{TELEREHABILITATION IN THE VETERANS HEALTH ADMINISTRATION}

Description: Telehealth is an effective and convenient way for patients to receive, and clinicians to provide, VA care. VA has implemented national telehealth quality and training resources to ensure local services from more than 900 VA locations and in over 50 specialty areas of care.

The VA supports a Telerehabilitation Enterprise Wide Initiative (TREWI) to enhance access to specialized rehabilitation services for rural Veterans through the development of a hub and spokes model system of care. Through four VA HUB sites (Seattle, San Antonio, Minneapolis and Richmond) and seven VA spoke sites the VA has addressed and developed a solution to provide access to Veterans in need of specialized rehabilitation.

The hub and spoke sites provide specialized rehabilitation services, clinical care and consultation through telehealth with special focus on developing telerehabilitation protocols and providing virtual care to address Veterans with traumatic brain injury (TBI), amputation, back pain and to promote assistive technology, health coaching and home safety evaluations to name only a few.

VA telerehabilitation champions provide clinical and technical education throughout the system of care and utilize specialized telerehabilitation protocols that outline a National standard-of-care.

Telehealth in VA is the forerunner of a wider vision in which the relationship between patients and the healthcare system is changed with the full realization of the connected patient. The high levels of patient satisfaction and positive clinical outcomes attest to this.
Reference: https://vaww.infoshare.va.gov/sites/telehealth/docs/ts-factsheet .pdf

SPEAKER: Lesli Culver (Veterans Health Administration - Tampa, FL), Jessica Barton (Veterans Health Administration - Richmond, VA), Grace Wilske (Veterans Health Administration - Minneapolis, MN), Amanda Olney (Veterans Health Administration - Seattle, WA)

Session Theme: The VA has pioneered a HUB and SPOKE model system of care for telerehabilitation across the nation using real-time, interactive video conferencing to provide care.

Key Learning Objectives:

1. Define telerehabilitation.

2. Identify telehealth service delivery options.

3. Acquire clinical best practices for telerehabilitation.

4. Identify benefits and outcomes of telerehab in regard to access and quality of care.

Key Actions for Participants to Implement:

1) How to develop and sustain a telerehabilitation program.

2) How to develop standardized telerehab protocols.

3) How to promote and market a telerehab program.

Keywords: telerehabilitation, Veteran, military, rural, government, clinical practice, guidelines, telehealth

\section{RD-65}

OCHSNER TELEHEALTH: USING SEGMENTATION, SOCIAL DETERMINANTS AND PATIENT-CENTERED CARE TO LAUNCH A SUCCESSFUL TELEHEALTH PROGRAM

Description: Louisianan's leverage many key ingredients to create the perfect gumbo, the same rings true with Ochsner Health System's Telehealth program! Ochsner Health System, Louisiana's largest non-profit academic healthcare system touches over 50,000 patients virtually each year. To gain traction both internally with health system providers and externally with partnering facilities and consumers, the health system launched a multifaceted telehealth engagement strategy. During this session, Ochsner will reveal best practices and lessons learned from their telehealth program, and discuss evolving strategies for the future.

SPEAKERS: April Radford (Ochsner Health System); Jennifer Humbert MSN, MHA, RN (Ochsner Health System); Ryan Pattison (Ochsner Health System)

Key Learning Objectives:

1. Deploys digital touch points to reach consumers where they already are.

2. Uses social determinants of health in patient-centered care.

3. Capitalizes segmentation data to target key patient populations Partners with multiple telehealth avenues to experiment and drive telehealth adoption

\section{RD-66}

\section{PAYER PANEL ON TELEHEALTH}

Description: Payers are entering risk-based contracts with health systems and physician groups, which are leveraging telemedicine to expand the 


\section{ROUNDTABLE DISCUSSION}

engagement opportunities with their patients. Adding telemedicine to their covered benefits also allows payers to enhance the customer experience of their members.

In 2020, Medicare Advantage plans will be able to offer seniors expanded telehealth services as a new test benefit. CMS wants to move beneficiaries into lower-cost, higher value healthcare services as a part of its value-based insurance design model. Telehealth can be an additional option to in-person visits. More than one third of seniors are now in MA plan and by 2025, it is estimated that nearly 50\% of those eligible for Medicare will be enrolled in MA plans.

SPEAKERS: Cathy Eddy (Health Plan Alliance Group); Vindell Washington, MD (Blue Cross Blue Shield of Louisiana); Tod Soderquiest (Humana); and Latoya Thomas (Doctor on Demand)

\section{Key Learning Objectives:}

1. Are including telehealth in their value-based contracts with providers.

2. Will look at ways to offer Medicare Advantage members telehealth as an additional option.

3. Can improve the member experience with a virtual care option as an alternative to physician office, urgent care and ER visits.

\section{RD-67}

\section{THE EVOLVING LANDSCAPE OF TELEHEALTH: POLITICS, POLICY, OPERATIONS AND OVERSIGHT}

Description: Through this interactive breakout session, attendees will discuss the political environment as it relates to telehealth policy and analyze changes in Medicare, Medicaid and Commercial Reimbursement Guidelines in areas such as Remote Patient Monitoring, Care Management, and Behavioral Health and the billing and operational (e.g., consent, licensing, supervision) challenges that the guidelines pose to deliver reimbursable services. Not only are there policy and reimbursement changes in telehealth, but also opportunities created by telehealth advancements and some value-based care models that enable healthcare providers to innovate care delivery. By modifying and expanding operations in new ways to improve quality of care and provide cutting edge medicine to diverse populations, providers are better equipped to reach vulnerable patients, including older adults and those aging in place, patients dealing with opioid and substance abuse issues, as well as women with reproductive health needs. However, such an ever-changing telehealth environment does not come without its own inherent risks, including increased government oversight and enforcement risks under various fraud and abuse laws.

SPEAKERS: Terrence Lewis (University of Pittsburgh Medical Center); Charlene MacDonald (FTI Consulting); Wayne Gibson (FTI Consulting; Health Solutions); and Kristen McDonald (Jones Day)

Session Theme: Keeping abreast of developments in the ever-changing world of telehealth, from regulation and reimbursement to operations to fraud and abuse mitigation.

Key Learning Objectives:

1. Overview of threats and opportunities facing telehealth in the current political environment. What does a divided government mean for the advancement of legislation and regulations intended to expand access to telehealth services? How can industry most effectively influence processes and policies in Washington?

2. Highlight changes and proposed changes in Medicare, Medicaid and Commercial Reimbursement Guidelines (e.g., Remote Patient Monitoring, Care Management, and Behavioral Health) and Challenges Posed in Navigating Guidelines to Provide Reimbursable Services.
3. Identify areas of highest potential risk for government fraud and abuse enforcement in telehealth.

Key Actions for Participants to Implement:

1. Engage effectively with policymakers.

2. Ask key questions regarding variations in reimbursement guidance, as well as regarding potential licensing and supervision hurdles.

3. Roll out new efforts to reach vulnerable patients.

Keywords: telehealth policy; telehealth reimbursement; telehealth government enforcement

\section{RD-68}

\section{FROM INFANCY TO MATURITY - SUSTAINABLE TELEHEALTH PROGRAMS IN ACADEMIC MEDICINE}

Description: Telehealth is considered the fastest growing segment of the healthcare market, growing 20\% to 50\% each year and expected to exceed $\$ 30$ billion in the next few years. While many organizations understand the value and potential of telehealth, fewer are able to implement programs that operate sustainably and at scale. In this session, a panel of telehealth leaders from four different Academic Medical Centers will describe successful, largescale telehealth programs and the many strategies they employed to reach maturity.

Programs discussed include video visits, e-consults, virtual consults and virtual case conferences, each of which has have been implemented at two or more of the participating institutions. While all these programs have met with success, the paths they took from conception to widespread adoption varied considerably between organizations.

This moderated discussion focuses on how:

- Programs were conceived, funded and initiated

- Growth is tracked and communicated

- Program goals are set, measured and re-set over time

- Challenges and barriers change over program lifetime

- Continuity is ensured, despite inevitable changes in staffing and technology

- The research and education missions of academic medicine are supported

There is no one "right way" to implement or operate a telehealth program. This panels gives attendees a unique opportunity to understand a broad array of strategies that have led to continued success.

SPEAKERS: Courtney Stevens (Henry Ford Health System); Juan Estrada (Massachusetts General Hospital); Linda Branagan (University of California, San Francisco); and John Scott, MD, MSc (University of Washington)

Session Theme: Telehealth in action - an opportunities for attendees to learn about mature telehealth programs at multiple institutions and the paths they took to get there.

Key Learning Objectives:

1. Collect insights from actual examples of recognized academic healthcare organizations that have developed well-adopted, highly-utilized telehealth offerings.

2. Discover challenges, barriers and pitfalls encountered by all four institutions, and how they were addressed and overcome.

3. Understand key program management and organizational change processes for achieving adoption, scalability and growth of telehealth programs.

Key Actions for Participants to Implement: 
1. Understand how 4 types of telehealth programs can support their organization's larger strategic goals.

2. Choose implementation and growth strategies that are appropriate for their own organization.

3. Predict barriers and roadblocks that will arise down the road and proactively prepare for them.

Keywords: sustainability, maturity, academic institution, video visits, virtual consultations, virtual case conferences, e-consults, organizational change

\section{RD-69}

\section{TELEMENTAL HEALTH “JEOPARDY" - UNDERSTANDING THE PAST, PRESENT, AND FUTURE OF THE DISCIPLINE}

Description: Behavioral health treatment is not only one of the fastest growing and most important use cases for telemedicine, but it is also a leader across the industry. Few other disciplines encounter, manage, and develop solutions to the same range of clinical and regulatory issues as telemental health.

This breakout session will follow a "Jeopardy-style" format where renowned telehealth experts, in partnership with the ATA Telemental Health Special Interest Group (TMH SIG), compete to be crowned the 2019 ATA Telemental Health "Jeopardy" Champion. The session will include 45-minutes of "Jeopardy" followed by a 15-minute question and answer session with our expert panelists. The session will be specific to the telemental health specialty area and inform the broader telemedicine community. Each topic will be identified by the TMH SIG as high-impact and high-priority and representing different aspects of a successful telemental health program. Topics will include at least the following:

- Telemental Health Start-up (How to Begin a Telemental Health Program)

- Let's Get Paid (Reimbursement and Business Models)

- Addiction Treatment (Telemedicine for Treating Addictions)

- Going Mobile (The Expanding Role of Mobile Applications)

- Policy Updates (2018 Policy Changes and Expectations for 2019)

- Best Practices (How Guidelines Guide Clinical Standards)

- Special Populations (Issues that Impact Specific Populations)

Learning points will include real-world lessons and practical implications based on current research, case studies, and applied experiences. This session is further designed to augment other telemental health presentations at the meeting and replace the TMH SIG pre-conference workshop. It is expected that the success of this breakout session will be replicated in future years.

SPEAKERS: Matt Mishkind, PhD (University of Colorado Johnson Depression Center); Jay Shore, MD, MPH (University of Colorado Department of Psychiatry); and Carolyn Turvey (University of Iowa, Department of Psychiatry)

Session Theme: Telemental health.

\section{Key Learning Objectives:}

1. Better understand the overall breadth of telemental health.

2. Gain expertise in understanding cutting edge themes, concerns, and issues facing telemental health.

3. Evaluate trends in telemental health.

Key Actions for Participants to Implement:

1. Explain telemental health as a field.

2. Evaluate current telemental health best practices.

3. Predict future telemental health trends.

Keywords: mental health, behavioral health, psychiatry

\section{RD-70}

\section{TIME IS BRAIN: KAISER PERMANENTE SOUTHERN CALIFORNIA REVAMPS TELESTROKE PROGRAM FOR EXTENDED THROMBECTOMY TREATMENT WINDOW}

Description: When it comes to treating stroke patients, intervention evidence and treatment guidelines are rapidly changing; Cleveland Clinic unveiled the "Expanded Window for Acute Stroke Intervention" as a Top 10 Medical Innovation for 2019. Additionally, many hospitals do not have neurologists physically on-call $24 / 7$ to provide assessments and order lifesaving medication. This presents an opportunity to quickly activate interdependence networks via video modalities, truly "Telehealth in Action."

This session walks through a large-scale implementation covering pitfalls and best practices alike.

1. We will review the Telestroke program, such as historical data, quality metrics and why immediate updates were necessary. KP SCAL implemented a 24/7 Telestroke Program in 2014, whereby neurologists video-in to hospitals through a telepresence cart. The program required a revamp to incorporate the newest 2018 AHA/ ASA Guidelines for Acute Ischemic Stroke, reflecting an extended window for potential thrombectomy candidates of up to 24 hours. We created a system and named it "CODE 24." Operationalizing the new guidelines meant taking care of more patients with the same number of resources.

2. As part of the session, we will walk through the implementation of PDSA cycle. Planning: A Regional Telestroke lead reviewed multiple processes and methodologies. Do: Brought the vision to executive leadership and telehealth operations team. Created workflows, training materials, resource guides, conducted a technology review and went on a roadshow with a Continuing Medical Education embedded presentation to educate all Emergency Department physicians.

Study: Iterative process, learned from the first two sites. Act: Constant improvements based on hospital-specific feedback.

3. To highlight the impact, we will review cases and outcomes.

4. Lastly, we will discuss how this work is ongoing and we continue to integrate new guidelines from clinical studies, while not disrupting systems. We will emphasize the importance of learning from other Telestroke programs and sharing best practices.

SPEAKERS: Navdeep Sangha (Kaiser Permanente); Jazmine Gutierrez, MPH (Kaiser Permanente); Amanda Hauser DeHaven, MPH (Kaiser Permanente)

Session Theme: Crucial synergy between teleneurologists' ability to quickly see patients remotely, with limiting factor of physically present critical care staff. Implementing updates without breaking current systems.

\section{Key Learning Objectives:}

1. Case study examination and analysis of how a Telestroke program updated with the 2018 American Heart Association/American Stroke Association (AHA/ASA) guidelines was quickly implemented in a large integrated healthcare system.

2. Understand complex system needs associated with integrating a new telemedicine-dependent workflow in a critical care setting. Identifying gaps in the system to successfully operationalize workflows that are constantly updated and yielding the treatment of more patients every year with finite staffing.

3. TeleNeurology is one part of an ecosystem, influenced by non-telemedicine operational factors, such as the pace of the Emergency Departments and existing protocols. An illustration of how participants can identify and promote collaboration among different departments to improve patient outcomes. 


\section{ROUNDTABLE DISCUSSION}

Key Actions for Participants to Implement:

1. Employ concrete materials such as workflows, clinician training video, guides and "badge buddies."

2. Apply best practices for division of labor and stakeholder adoption.

3. Appraise systems requiring symbiotic relationship between telemedicine modalities and nursing staff physically with the patient. Identify limiting factors and how to approach solving them.

Keywords: telepresence, interdependence, telestroke

\section{RD-71}

\section{A MODEL FOR EDUCATING AND TRAINING VIRTUAL CARE PROVIDERS}

Description: Traditional medical and healthcare education does not currently embrace strategies for integrating the education and training of students or professionals in areas specifically related to virtual care delivery. The argument has been made that a training addendum is required to "all" healthcare professionals who intend to practice in the future because of the increasingly ubiquitous use of technology. Elements of the training include: health informatics, artificial intelligence and machine learning, social media, immersive media, the psychology of virtual communications, virtual team management, operational requirements for remote care delivery, technology trends, legal/regulatory/privacy/security requirements, among other considerations.

SPEAKERS: Kevin Fickenscher, MD (CREO Strategic Solutions, LLC); David Schmitz, MD; Susan Fenton, PhD; and Jacob Childers, MD

Key Learning Objectives:

1. Outline the key training requirements in providing effective virtual care delivery.

2. Define the core education and training modules for virtual care providers.

3. Outline the rationale and approach for supporting an inter-university model of education.

Keywords: virtual, clinical, education

\section{RD-72}

\section{DIRECT-TO-CONSUMER TELEMEDICINE - LESSONS LEARNED AND STRATEGIES FOR ADVANCING POLICY}

Description: Consumers today have higher expectations when it comes to telemedicine service and delivery models, and consumers are willing to pay for services that can meet these expectations. For example, many consumers seek to use telemedicine to address a specific medical issue. As a result, consumers are attracted to platforms that are designed and targeted to address these specific issues, such as obtaining contraception or treating herpes or erectile dysfunction. Consumers also have preferences about how they engage with physicians. While some may prefer a video chat or a phone call, many consumers are comfortable with (or prefer) asynchronous interactions, especially where they have not previously met with the physician in person. In an asynchronous encounter, consumers are able to review and enter information at their own pace and on their own time and then receive detailed written instructions and feedback from their treating physician. Finally, consumers want more than just a physician visit. Consumers want to engage with physicians and services that can review their medical records, diagnose their condition (including ordering a lab test as necessary to do so), prescribe medication or treatment, and work with a pharmacy to deliver medication right to the consumer's door.

Industry has responded to these consumer demands at a rapid race. Unfortunately, many state regulators have not kept up. While state regulators serve an important role in protecting patient safety, many of the state statutes and regulations that are on the books today, even those that were enacted in just the last few years, do not contemplate more consumer-friendly telemedicine models. This can result in increased scrutiny or pushback on nontraditional telemedicine models that nonetheless meet or exceed the standard of care. Thus, direct-to-consumer telemedicine companies must engage with and educate regulators about new delivery models.

During this session, we plan to discuss (1) changing consumer preferences and industry response; (2) gaps in state statutes and regulations, and (3) strategies for engaging state regulators.

SPEAKERS: Laura Koman (Jones Day) and Adam Greenberg (Ro); Lina Brenner (Nurx); and Quinn Shean (Tusk Venture)

Session Theme: Trends and ideas that are driving the industry and the regulatory response: asynchronous-only modalities, condition-specific platforms, and pharmacy integration in direct-to-consumer telehealth models.

Key Learning Objectives:

1. Consumers today expect more than just a cool smartphone app. To stay relevant and competitive, direct-to-consumer telemedicine platforms need to think outside the box about platform design, consumer technology/communication preferences, and expanding service offerings to incorporate services like lab testing and pharmacy fulfilment.

2. Direct-to-consumer telemedicine is not just for millennials. Userfriendly platforms and condition-specific offerings addressing issues like hot flashes, insomnia, and erectile dysfunction appeal to older adults and aging populations.

3. Regulators have not kept up with evolving consumer preferences and industry adjustments. Engaging with (and educating) regulators about new service models and structures is important.

Key Actions for Participants to Implement:

1. Think Outside of the Box: consider ways to adapt offerings to meet consumer demands and expectations.

2. Engage: engage with consumers directly to gather feedback on your business.

3. Impact: consider opportunities for regulator engagement regarding your business lines.

Keywords: direct-to-consumer, asynchronous, telemedicine policy

\section{RD-73}

\section{IMPACT OF TELECARE TECHNOLOGY ON THE HEALTHCARE WORKFORCE}

Description: The use of telecare technologies is rapidly altering the approach toward the delivery of care in all healthcare settings - from acute care to long term care to ambulatory environments. With the looming entrance of a vastly increased elder population and projected decrease in supply of care providers - one of the major questions is whether or not technology can be used to supplant traditional methods of care delivery. The panel will present a variety of perspectives, debate the potential outcomes of new delivery patterns in administering care and, discuss impediments that need to be addressed to resolve any conflicting issues. 


\section{ROUNDTABLE DISCUSSION}

SPEAKERS: Til Jolly, MD (SOC Telmed); Tim Dall (IHS Markit); Karen Deli (InTouch Health); Griffin Mulcahey (Enzyme Health); Mia Finkelston, MD (American Well)

\section{Key Learning Objectives:}

1. Outline the projected workforce demands in healthcare.

2. Define the teleservice impact on efficiency and effectiveness in care delivery.
3. Outline the potential impact on technologies on workforce demand in value-based care delivery environments.

Key Actions for Participants to Implement:

1. Apply workforce demand models in conjunction with the teleservices and who to contact for further information.

Keywords: Virtual, Workforce, Development, Impact 